\title{
Optimal Reconfiguration of Distribution Network in Presence of D-STATCOM and Photovoltaic Array using a Metaheuristic Algorithm
}

\author{
Kola Sampangi Sambaiah and T Jayabarathi
}

\begin{abstract}
In this paper, grasshopper optimization algorithm (GOA) a novel meta-heuristic optimization algorithm is used to solve the network reconfiguration problem in presence of distribution static compensator (D-STATCOM) and photovoltaic (PV) arrays in a distribution system. Here, DSTATCOM acts as distribution flexible ac transmission (DFACT) device and PV arrays as decentralized or distributed generation (DG). The main purpose of the present research includes power loss minimization and voltage profile (VP) enhancement in radial distribution systems under different loading conditions. The proposed GOA is based on swarming behavior of grasshoppers in nature. The proposed GOA is validated using the standard 33, 69 and 118 - bus test systems. The simulation results proved that the optimal network reconfiguration in presence of D-STATCOM units and PV arrays leads to significant reduction in power loss and enhancement in VP. The results obtained by the proposed GOA are compared with base value and found that the optimal network reconfiguration in presence of D-STATCOM and PV arrays is more beneficial than individual objective optimization. Also, the proposed GOA is more accurate, efficient and reliable in finding optimal solution when compared to existing modified flower pollination algorithm (MFPA), firework algorithm (FWA), fuzzy-based ant colony optimization (ACO) and genetic algorithm (GA).
\end{abstract}

Index Terms- Distribution Systems, D-STATCOM installation, Network Reconfiguration, Power loss Minimization, PV arrays allocation.

\section{INTRODUCTION}

Nowadays, distribution systems are receiving more attention from distribution network operators (DNO) and researchers due to its technical, economic and environmental benefits. Due to radial structure power losses are more in distribution systems when compared to transmission systems. It is observed that for a fixed network configuration with varying load conditions in a distribution system power loss will not be minimum. Hence, there is a need for timely network reconfiguration to minimize power loss and relieve network overloading. There are two lines present in a primary distribution network namely sectional switches (normal closed condition) and tie switches (normal open condition). The process of altering the topological structure of distribution feeders through varying open/closed

Published on September 27, 2020

Kola Sampangi Sambaiah, Research Scholar, School of Electrical Engineering, Vellore Institute of Technology, India.

(corresponding e-mail: sambaiahks ${ }^{\circledR}$ gmail.com).

T Jayabarathi, Senior Professor, School of Electrical Engineering, Vellore Institute of Technology, India.

(e-mail: tjayabarathi@vit.ac.in). condition of sectional and tie switches is known as network reconfiguration. Reconfiguration is preferred in low voltage distribution networks. The main advantages of reconfiguration are:
a. power loss minimization
b. service restoration during feeder faults
c. relieve network overloading
d. voltage profile enhancement and
e. network maintenance through planning outages

Since reconfiguration is a complex combinatorial constrained optimization problem, several researchers have proposed various algorithms in the past. Merlin and Back [1] first proposed the concept of network reconfiguration and they used branch and bound method for optimizing. However, the method has to solve $2^{n}$ possible system configurations, where $n$ is the total number of line switches which is a time consuming process. Shirmohammadi and Hong [2] proposed a heuristic algorithm which is based on the method of Merlin and Back [1]. The main drawback of this algorithm is simultaneous switching operation is not considered. Civanlar et al [3] presented a heuristic algorithm based on a simple mathematical formula which determines the change in power loss during the process of branch exchange. However, in this method network reconfiguration is depends on initial switch status and it considers only the sole pair of switching operation. Baran and $\mathrm{Wu}$ [4] suggested a simple search method for reconfiguration with load balancing based on branch exchange and two load flow methods for evaluating network power loss.

However, the method has to solve $m^{2}$ possible system configurations, where $m$ is the total number of line switches and it has to solve $m$ power flow solutions which are a timeconsuming process. In recent years the researchers have proposed numerous methods for distribution system reconfiguration considering reliability enhancement and power loss reduction are available in the literature [5]. Recently, Sarantakos et al [6] suggested cost-based analysis for component condition and substation reliability enhancement through network reconfiguration. However, due to increasing load, the distribution system demand is more than generation capacity which makes it impossible to relieve loads on the feeders. Also, only reconfiguration is not suitable for improving voltage profile to the optimal level. Hence distributed generation (DG) units are integrated into distribution system to meet the increasing load demand, to manage the network performance, operation, and control. 
In many countries across the world deregulation of electricity markets offers new perspective for distributed or decentralized or local generation of electrical energy through renewable energy sources with small capacity. Typically, the capacity of DG units is from $5 \mathrm{~kW}$ to $10 \mathrm{MW}$. Generally, DG units are installed closer to the end-consumer to provide electric power. The DG units may be combustion turbines, micro turbines, wind turbines, fuel cell and solar photovoltaic (PV) etc.., so that the total or a part of distribution system load demand can be served. The optimal allocation (location and size) of DG will minimize the power loss, enhances voltage profile (VP), improves power quality and reliability of the system. However, inappropriate allocation of DG units will impact the system performance adversely. Since optimal allocation of DG is also a complex combinatorial constrained optimization problem several methods have been proposed by various researchers in the recent past [7]. These methods are often based on analytical, classical, heuristic or meta-heuristic and artificial intelligence algorithms. Mahmoud et al [8] proposed an efficient analytical method for optimal allocation of different DG units to minimize network power loss. Jeddi et al [9] proposed a robust optimization framework based on harmony search algorithm for planning of dynamic distributed energy resources in distribution systems. Saha et al [10] proposed a chaos embedded symbiotic organisms search algorithm for DG allocation in a radial distribution system for loss minimization and VP enhancement. Sanjay et al [11] proposed a hybrid algorithm which is a combination of grey wolf optimizer and differential evolution operators called hybrid grey wolf optimizer for optimal allocation of different DG types based on nature of power injection for achieving power loss minimization.

Rao et al [12] proposed a meta-heuristic technique called harmony search algorithm to analysis the performance of simultaneous reconfiguration and DG allocation for power loss minimization and VP enhancement. Esmaeilian et al [13] proposed the concept of integrating genetic algorithm and improved switch exchange method for achieving network minimum loss configuration in the presence of DG units. Esmaeil et al [14] proposed an enhanced gravitational search algorithm for simultaneous reconfiguration and DG allocation with the objectives of enhancing transient stability, minimizing operational cost and power loss in the distribution system. Moreover, various techniques used for reconfiguration in the presence of DG units in distribution systems for loss minimization and VP enhancement are discussed in [15]-[19].

Distribution flexible ac transmission system (D-FACT) devices are considered as imperative equipment in distribution systems with several application and controlling techniques for enhancing the power quality indices. Distribution static compensator (D-STATCOM), dynamic voltage restorer (DVR), unified power flow controller (UPFC) are widely used D-FACT devices. These devices play a vital role in overcoming distribution problem through a substantial reduction in power loss, VP enhancement and power factor correction in distribution systems. The optimal allocation of D-STATCOM will provide reactive power support to the distribution system. Since the optimal allocation of D-STATCOM is also a complex combinatorial constrained optimization problem several researchers have proposed various techniques. Farhoodnea et al [20] proposed a firefly algorithm for optimal allocation of D-STATCOM in distribution system for power quality improvement. Taher and Afsari [21] presented an immune algorithm for power loss minimization and enhancement of VP and current profile in distribution network. Yuvaraj et al [22] presented a harmony search algorithm for optimal allocation of D-STATCOM with total network loss minimization as objective. Devi and Geethanjali [23] presented the particle swarm optimization algorithm for power loss minimization through simultaneous allocation of DG and D-STATCOM in distribution systems. Devabalaji and Ravi [24] presented a bacterial foraging optimization algorithm for simultaneous allocation of DG and D-STATCOM in radial distribution systems with different load models. El-Ela et al [25] proposed water cycle algorithm for optimal allocation of DG and D-STATCOM in radial distribution systems for achieving techno-economic and environmental benefits.

In addition, several techniques have been proposed for loss minimization and VP enhancement among these techniques' simultaneous reconfiguration and optimal DG allocation or D-STATCOM allocation are most commonly used in the literature. However, only few researchers have focused on network reconfiguration in presence of both DG and DSTATCOM.

In this paper, the grasshopper optimization algorithm (GOA) has been used for solving optimal network reconfiguration problem in presence of D-STATCOM and PV arrays in radial distribution systems. The main objective of the present work includes loss minimization and enhancement of VP in the network under different loading conditions. The present algorithm has been tested on standard 33, 69 and 118 - bus test systems. The simulated results obtained by the proposed GOA are compared with base case and other existing methods available in the literature.

\section{PROBLEM FORMULATION}

\section{A. Power Flow Equations}

In this paper, for evaluating the system power flow the direct approach method is used [26]. The power flow calculation is constructed from the bus injection to branch current (BIBC) matrix and branch current to bus voltage matrix and their multiplication matrix. The direct approach for power flow is based on the equivalent current injection (ECI). The set of basic recursive equations are derived from the single line diagram shown in Fig. 1 for calculating distribution system power flow. From Fig. 1, the ECI at node $i$ is calculated as

$$
I_{i}=\left(\frac{P_{L i}+j Q_{L i}}{V_{i}}\right)^{*}
$$

By Kirchhoff's current law, the branch current in the line section $i$ is evaluated as

$$
J_{i}=I_{i+1}+I_{i+2}
$$




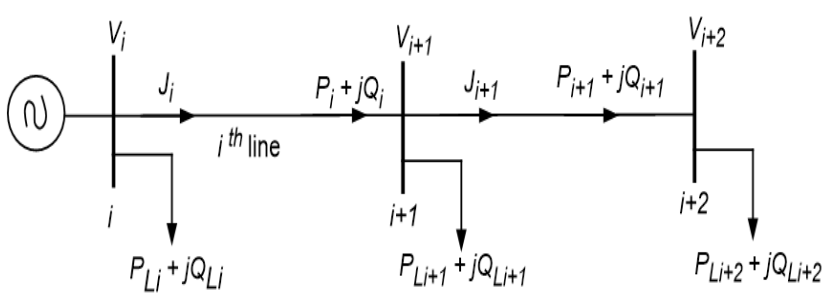

Fig. 1. Sample distribution feeder.

The equation (2) is generalized in a matrix form by using BIBC. Now at each line section the branch current branch can be evaluated in a matrix form as follows:

$$
[J]=[B I B C] *[I]
$$

By Kirchhoff's voltage law, the voltage at the bus $i+1$ can be evaluated as

$$
V_{i+1}=V_{i}-J_{i} *\left(R_{i}+j X_{i}\right)
$$

The power loss in the line section $i$ connecting between buses $i$ and $i+1$ is evaluated as:

$$
P_{\text {loss }}(i, i+1)=\left|J_{i}\right|^{2} * R_{i}=\left(\frac{P_{i}^{2}+Q_{i}^{2}}{V_{i}^{2}}\right) * R_{i}
$$

The system overall power loss is evaluated by the summation of line losses in all line sections, which is given as:

$$
P_{T, \text { loss }}=\sum_{i=1}^{n} P_{\text {loss }}(i, i+1)
$$

\section{B. Network Reconfiguration}

For reconfiguration problem, the radial structure of the network is considered as an imperative constraint. Hence, during reconfiguration to maintain the radial structure of the network, it is necessary to order distribution system nodes optimally in order to generate parent node-child node path as given in [27]. This path generation will retain the radial structure of the network, also avoids the formation of mesh loops and the creation of unconnected branches or nodes. Therefore, at each level of network reconfiguration, the power flow is evaluated only after the generation of appropriate parent node-child node path of the network. The generation of parent node-child node path for the sample distribution system shown in Fig. 2 is present in Table I.

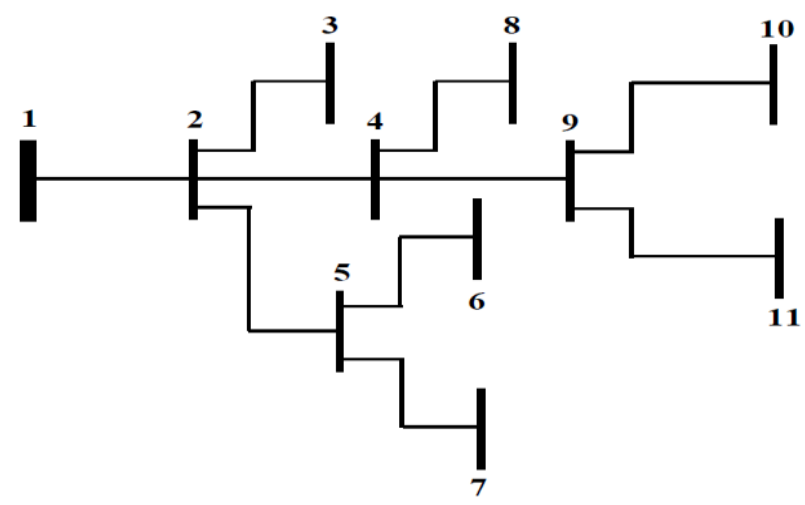

Fig. 2. Sample distribution system.
TABLE I: REPRESENTATION OF PARENT NODE-CHILD NODE PATH GENERATION

\begin{tabular}{ccccccccccc}
\hline $\begin{array}{c}\text { Parent } \\
\text { node }\end{array}$ & 1 & 2 & 2 & 2 & 5 & 5 & 4 & 4 & 9 & 9 \\
$\begin{array}{c}\text { Child } \\
\text { node }\end{array}$ & 2 & 3 & 4 & 5 & 6 & 7 & 8 & 9 & 10 & 11 \\
\hline
\end{tabular}

In a distribution system, the network reconfiguration problem is solved to identify the optimal structure of the network that gives minimum power loss by satisfying imposed system operating conditions of system voltage profile, feeder current carrying capacity and radial structure of the distribution system. The power loss in the line section $i$ connecting between buses $i$ and $i+1$ after system reconfiguration is evaluated as

$$
P_{\text {loss }}^{\prime}(i, i+1)=\left|J^{\prime}{ }_{i}\right|^{2} * R_{i}=\left(\frac{P_{i}^{\prime}+Q_{i}^{\prime}}{\left|V_{i}^{\prime}\right|^{2}}\right) * R_{i}
$$

The reconfigured system overall power loss is evaluated by the summation of line losses in all line sections, which is given as

$$
P_{T, l o s s}^{\prime}=\sum_{i=1}^{n} P_{\text {loss }}^{\prime}(i, i+1)
$$

The system net power loss $\Delta P_{\text {loss }}^{R}$, is the difference of the power loss obtained before and after system reconfiguration, i.e., eq (6)-eq (8)and can be given as

$$
\Delta P_{\text {loss }}^{R}=\sum_{i=1}^{n} P_{\text {loss }}(i, i+1)-\sum_{i=1}^{n} P_{\text {loss }}^{\prime}(i, i+1)
$$

In order to enhance the voltage profile of the system, the voltage deviation must be minimized. This index maintains the configuration which gives the lower voltage deviation [28]. The voltage deviation index $\Delta V_{D}$ can be represented as

$$
\Delta V_{D}=\min \left(\frac{V_{1}-V_{i}}{V_{1}}\right) \forall i=1,2, \ldots, n
$$

The proposed algorithm will try to maintain the value of $\Delta V_{D}$ closer to zero and thereby enhances the system voltage stability without violating the voltage limits.

\section{PV Array Allocation}

Optimal allocation of PV arrays in the distribution network will minimize power losses, enhances voltage profile, avoids feeder overloading and have minimum impact on environment. A sample PV array is connected to AC mains supply through an inverter, main fuse box, and meter as shown in Fig. 3. After allocation of PV array, the active and reactive powers of the system can be calculated by following equations [29]:

$$
\begin{aligned}
& P^{P V}=\left[\frac{V_{i}^{2}}{R_{i}} P_{\text {loss }}^{P V}-\left(P_{i}^{2}+Q_{i}^{2}\right)-\left(Q_{P V}^{2}-2 P_{i} P_{P V}-\right.\right. \\
& \left.\left.2 Q_{i} Q_{P V}\right)\left(\frac{G}{L}\right)\right]^{1 / 2} \\
& Q^{P V}=\left[\frac{V_{i}^{2}}{R_{i}} P_{\text {loss }}^{P V}-\left(P_{i}^{2}+Q_{i}^{2}\right)-\left(P_{P V}^{2}-2 P_{i} P_{P V}-\right.\right. \\
& \left.\left.2 Q_{i} Q_{P V}\right)\left(\frac{G}{L}\right)\right]^{1 / 2}
\end{aligned}
$$




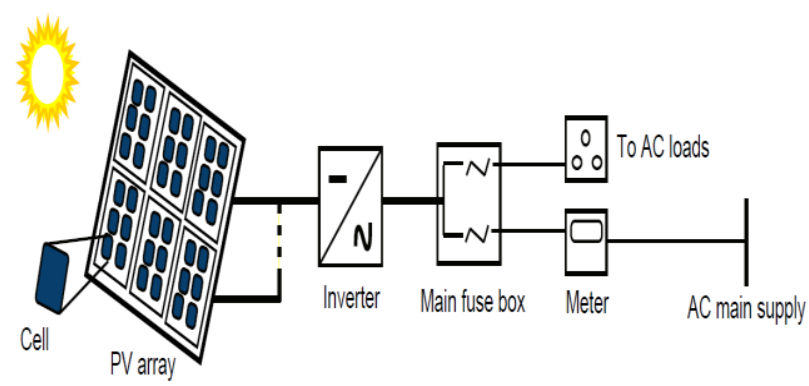

Fig. 3. Sample PV array connected to AC main supply.

\section{D-STATCOM Installation}

The D-STATCOM is a D-FACT device which consists of a DC capacitor, a GTO/IGBT voltage source converter (VSC), and a coupling transformer with a leakage reactance [30]. Fig. 4 illustrates D-STATCOM installed at bus $i+1$ of a distribution feeder. The reactive power flow in the distribution transformer windings can be minimized by the DSTATCOM capacity. The active power is set to zero and reactive power of the system after D-STATCOM allocation can be calculated by following equation [30]:

$$
Q^{D-S T A T C O M}=\left(\frac{V_{i}^{2}}{X_{L}}\right)-\left(\frac{V_{i} V_{M}}{X_{L}}\right) \cos \delta
$$

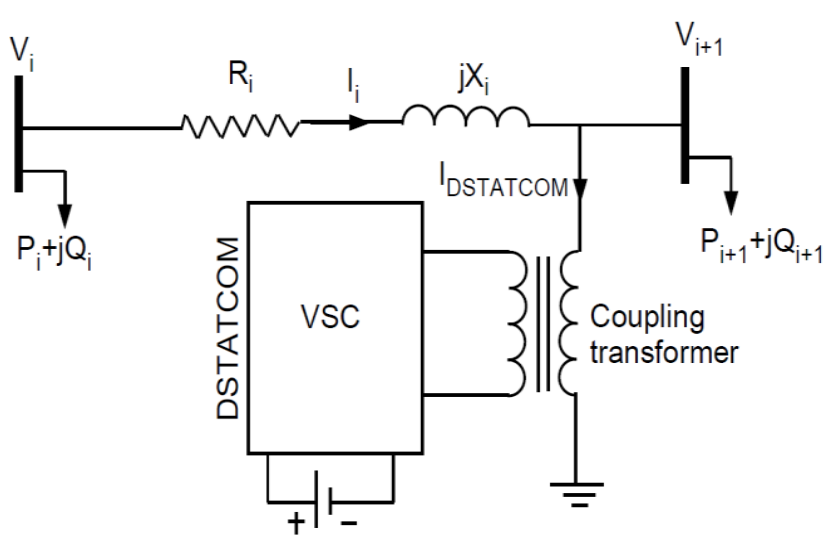

Fig. 4. D-STATCOM installed at bus $i+1$.

\section{E. Objective Function}

The main objective of the proposed method is to identify an optimal configuration for the distribution network, DSTATCOM and PV array allocation for minimization of loss and enhancement of VP. The objective function used to minimize the power loss in the distribution system is given as

Minimize $F=\min \left(\Delta P_{\text {loss }}^{R}+\Delta P_{\text {loss }}^{D-S T A T C O M}+\Delta P_{\text {loss }}^{P V}\right)$

Subjected to following constraints:

$$
\begin{aligned}
& V_{i}^{\min } \leq V_{i} \leq V_{i}^{\max } \\
& \sum_{i=1}^{n} P_{i}^{P V} \leq \sum_{i=1}^{n}\left(P_{i}+P_{i, \text { loss }}\right) \\
& \sum_{i=1}^{n} Q_{i}^{D-S T A T C O M} \leq \sum_{i=1}^{n}\left(Q_{i}+Q_{i, \text { loss }}\right) \\
& 0_{k W} \leq P_{k W}^{P V} \leq 2000_{k W} \\
& 0_{k V A r} \leq Q_{k V A r}^{D-S T A T C O M} \leq 1900_{k V A r}
\end{aligned}
$$

$$
\left.\begin{array}{c}
\operatorname{det}(A)=1 \text { or }-1 \text { (radial network }) \\
\operatorname{det}(A)=0(\text { not radial })
\end{array}\right\}
$$

The above constraint will check the radial structure of the network by energizing all the nodes [30].

\section{OVERVIEW OF GRASSHOPPER OPTIMIZATION ALGORITHM}

Grasshopper optimization algorithm was proposed by Saremi et al [31] in 2017. Grasshoppers are insects which cause damage to crop production and cultivation. Fig. 5 shows the life of grasshoppers. The optimization algorithm is based on the swarming behavior of grasshoppers in nature.

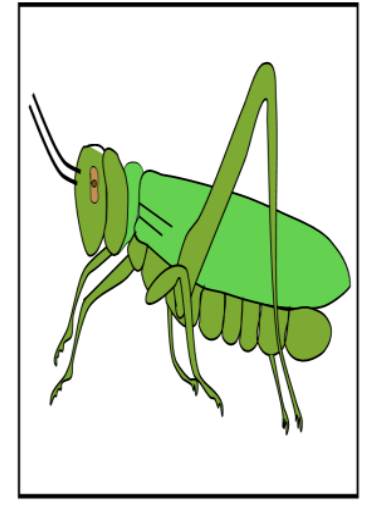

(a)

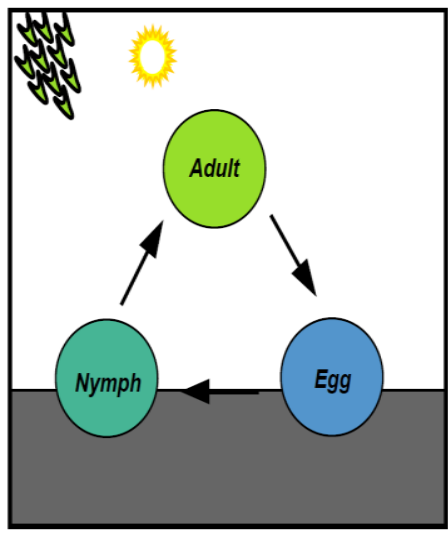

(b)
Fig. 5. (a) Grasshopper (b) Life cycle of grasshoppers

The mathematical model for solving optimization problems based on swarming behavior of grasshoppers is represented as follows

$X_{j}^{D}=c\left[\sum_{\substack{k=1 \\ k \neq j}}^{N} c\left(\frac{U B_{D}-L B_{D}}{2}\right) s\left(\left|x_{k}^{D}-x_{j}^{D}\right|\right) \frac{x_{k}-x_{j}}{D_{j k}}\right]+\widehat{T}_{D}$

where $U B_{D}$ and $L B_{D}$ are the upper and lower bound in the $D^{\text {th }}$ dimension, respectively. $x_{k}$ and $x_{j}$ are $k^{\text {th }}$ and $j^{\text {th }}$ position of grasshoppers, $x_{k}^{D}$ and $x_{j}^{D}$ are the positions of $k^{t h}$ and $j^{t h}$ grasshoppers in the $D^{t h}$ dimension, respectively. $N$ is the population size of the grasshoppers, $\widehat{T}_{D}$ is the target value in the $D^{\text {th }}$ dimension.

The adaptive component $c$ first (outside bracket) present in the equation (21) is used to stabilize the exploration and exploitation of the whole swarm towards the target or best value. In addition, the component $c$ (inside bracket) is decreasing coefficient for reducing attraction zone, repulsion zone and comfort zone between the grasshoppers.

For stabilizing the exploration and exploitation the component $c$ has to be reduced linearly along with iterations. This process helps in exploitation as the iteration increases. The relation between component $c$ and number of iterations is given by:

$$
c=\left(c_{\max }-m\right)\left(\frac{c_{\max }-c_{\min }}{\text { iter }_{\max }}\right)
$$

where $c_{\max }$ and $c_{\min }$ is the maximum and minimum value of component $c$, respectively. $m$ indicates current iteration and 
iter $_{\max }$ is the maximum number of iterations. Fig. 6 shows the pseudo-code of the GOA.

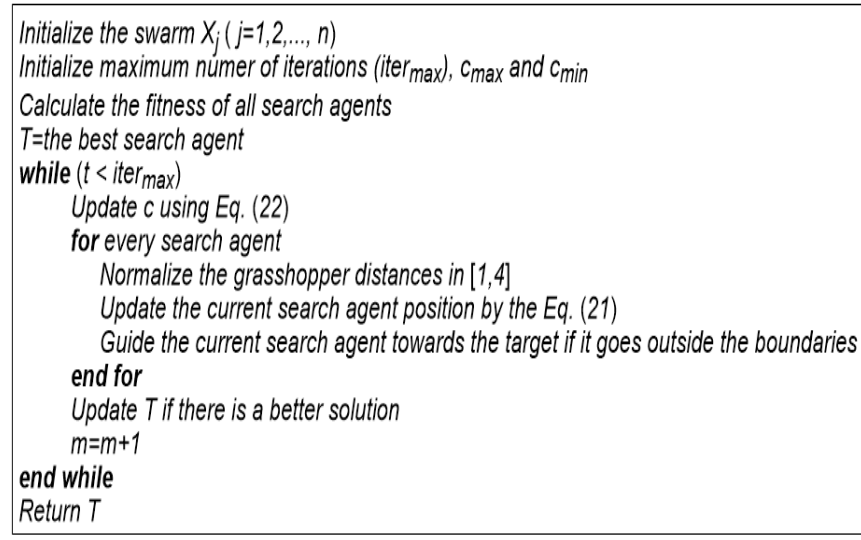

Fig. 6. Pseudocode of the GOA.

It is observed that GOA has the ability to explore the promising regions of the search space and cluster around the global optima eventually. These make the GOA suitable for solving complex combinatorial constrained optimization problems with increased accuracy and convergence. Sultana et al [32] recently used GOA for solving distribution system optimization problem of identifying the optimal location and sizing of multiple DG and battery swapping stations

\section{IMPLEMENTATION OF GOA FOR NETWORK RECONFIGURATION IN THE PRESENCE OF D-STATCOM AND PV ARRAYS}

The sequence of steps involved in distribution network optimization using GOA is presented as follows:

Step 0: Initialization of the GOA parameters;

iter $_{\text {max }}$ : maximum number of iterations;

$D$ : dimensions of search space i.e. number of tie lines or open switches, number of D-STATCOM units and PV arrays to be installed.

Generate the initial swarm of size equal to search space dimensions which satisfies all the constraints listed in section 2.4 .

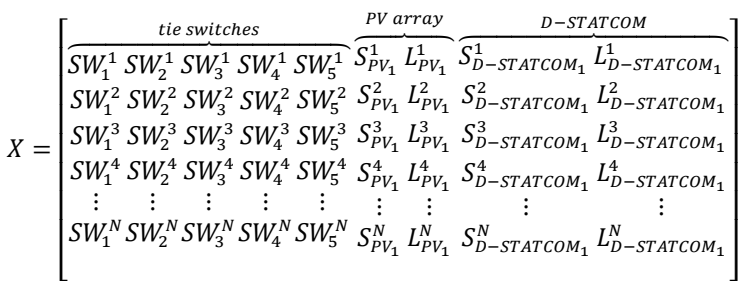

wherein the above Eq. (24) the first portion $\left(S W_{1}, S W_{2}, S W_{3}, S W_{4}\right.$ and $\left.S W_{5}\right)$ of the solution, vector represents the tie switches or open switches, second portion $\left(S_{P V_{1}}\right.$ and $\left.L_{P V_{1}}\right)$ represents the size and location of PV array and the third portion $\left(S_{D-S T A T C O M_{1}}\right.$ and $\left.L_{D-S T A T C O M_{1}}\right)$ represents the size and location of the D-STATCOM unit. However, for the 118 - bus distribution system the number of tie switches are 15, number of locations considered for PV arrays and D-STATCOM units for integration is six.

Step 1: Provide the required input data for load flow program which are base MVA, line voltage, line and bus data.
Step 2: Evaluate the value of the component $c$ using the Eq. (22) for each and every iteration.

Step 3: Update the current search agent position by the Eq. (21) for guiding the grasshopper towards the fitness (target) value.

Step 4: Evaluate the objective function $F$ using the Eq. (14) through load flow without violating the operational constraints.

Step 5: Adjust the position of search agents and update the fitness (target) value if the current solution is better than the solution obtained so far.

Step 6: Check for the stopping criterion. If the current iteration number is equal to maximum iterations then display the fitness (target) value and corresponding tie switches, location and size of and D-STATCOM and PV array. Otherwise, repeat the steps 2 to 5 .

The sequence of steps employed for solving network reconfiguration problem in presence of D-STATCOM and PV array using GOA is clearly illustrated in Fig. 7.

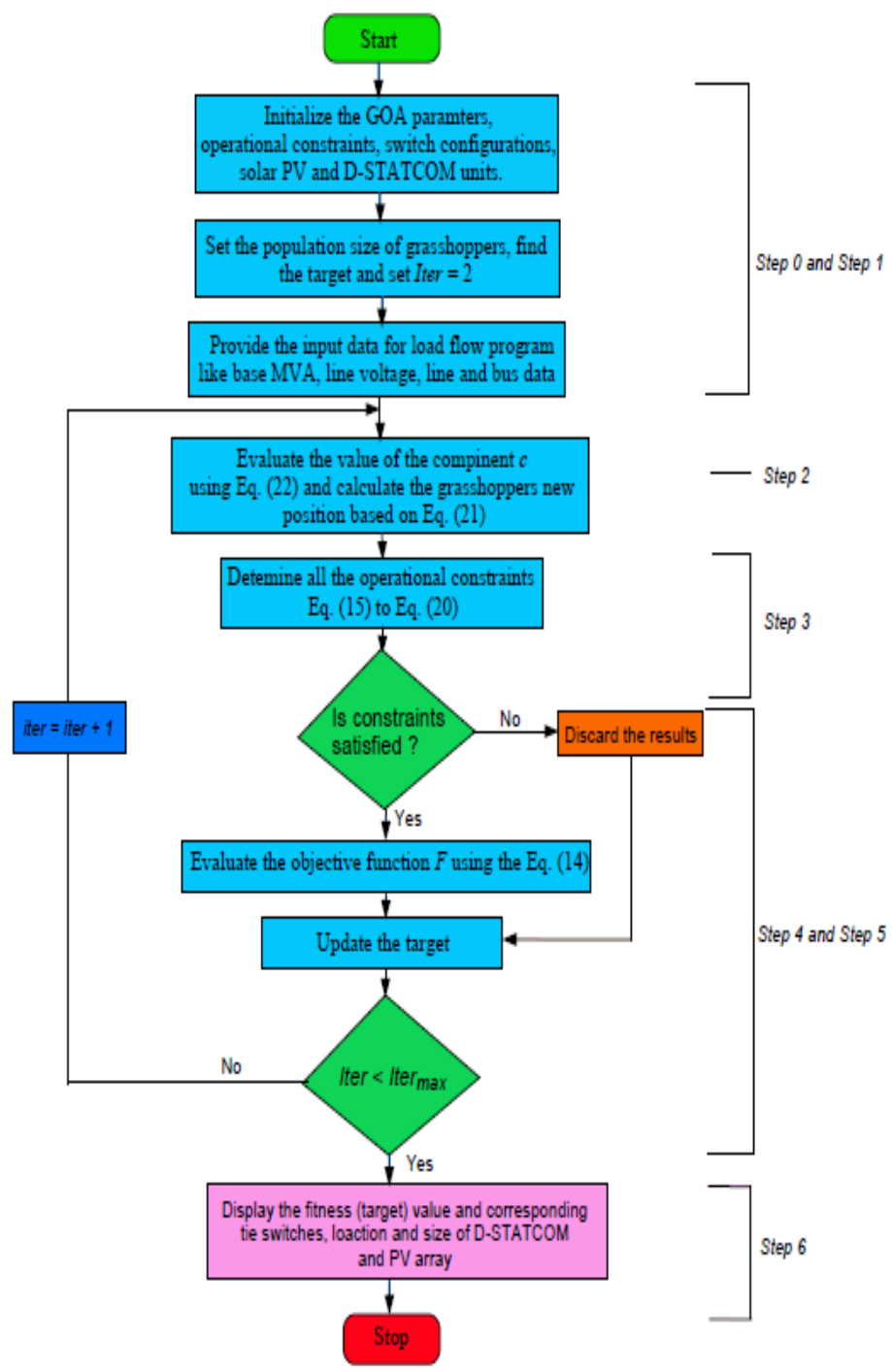

Fig. 7. Flow chart of the GOA.

\section{Simulation AND Numerical Results}

In order to demonstrate and validate the effectiveness of the present method (network reconfiguration in presence of D-STATCOM and PV array) using GOA, it is applied to 
three test systems consisting of 33, 69 and 118 - buses. In this paper, six different cases are considered to analyze the superiority of the proposed method.

Case 1: The system with standard configuration without DSTATCOM and PV array installation (base case)

Case 2: The system is reconfigured by the available tie and sectional switches.

Case 3: After system reconfiguration (i.e. case 2) DSTATCOM are installed.

Case 4: After system reconfiguration (i.e. case 2) PV array is installed.

Case 5: The system with a standard configuration with DSTATCOM and PV array installation.

Case 6: The optimal network reconfiguration in presence of D-STATACOM and PV array (optimum case).

All cases are programed in MATLAB ${ }^{\circledR}$ and simulations are performed in a computer with core i3, $2.9 \mathrm{GHz}, 4 \mathrm{~GB}$ RAM. To assess the proposed method performance the system is simulated at three different loading conditions: light $(0.5)$, nominal (1.0) and heavy (1.6).

\section{A. Test System 1}

The proposed method is initially applied on 33 - bus system having 5 tie switches (open switches) and 32 sectional switches (closed switches). The system total active and reactive power demands are $3.7 \mathrm{MW}$ and 2.3 MVAR, respectively. The power flow analysis is evaluated based on $S_{\text {base }}=100 \mathrm{MVA}$ and $V_{\text {base }}=12.66 \mathrm{kV}$. The system line and load data are taken from [33]. In this paper, DSTATCOM acts as a reactive power source and PV array as DG. The limits of D-STATCOM and PV array sizes chosen for installation at candidate bus locations were $0-1900 \mathrm{kVAr}$ and $0-2 \mathrm{MW}$, respectively. The numerical results obtained for 33 - bus test system using GOA for six tested cases under three different loading conditions are presented in Table II. It is observed that the base case power loss (in $\mathrm{kW}$ ) of the system at light load is 47.07 which is reduced to $33.27,24.56$, $23.71,12.64$ and 10.64 using case 2 to 6 , respectively. The percentage loss reduction obtained for case 2 to 6 is 29.31 , 47.82, 49.62, 73.14 and 77.39, respectively.

Similarly, the percentage power loss reduction obtained for case 2 to 6 at nominal and heavy load conditions are 31.14, 49.76, 51.59, 72.51 and 82.72; 33.47, 52.57, 54.40, 69.98 and 77.70 , respectively. It can be noticed that the power loss reduction using case 6 for all three load level, is highest, this elicits the proposed GOA is superior to other existing methods.

From Table II, it can be observed that the base case minimum bus voltage is 0.9131 p.u at bus 18 and voltage deviation index value of 0.0831 p.u. The improvement in minimum bus voltage $(p . u)$ and reduction in voltage deviation index $(p . u)$ at nominal load conditions for case 2 to 6 are $0.9378,0.9475,0.9479,0.9549$ and $0.9669 ; 0.0621$, $0.0376,0.0277,0.0217$ and 0.0038 , respectively. From this, it is noticed that improvement in minimum bus voltage and reduction in voltage deviation index are highest in case 6 . The optimal configuration of the distribution system for case 6 is shown in Fig. 8. Power loss convergence characteristic of the proposed GOA for 33 - bus system at nominal load is illustrated in Fig. 9. The voltage profile characteristics of case 1 (base case) and case 6 (optimum case) at nominal load level are illustrated in Fig. 10. The line loss reduction for case 1 to 6 is illustrated in Fig. 11. It can be noticed that the line losses reducing drastically for case 1 to 6 at nominal load level.

The simulated results obtained using the proposed GOA at nominal load level are presented in Table III and the same is compared with other methods existing in the literature. From Table III, it can be observed that the proposed GOA is performing better than the other existing methods in terms of power loss minimization and VP enhancement for all cases.

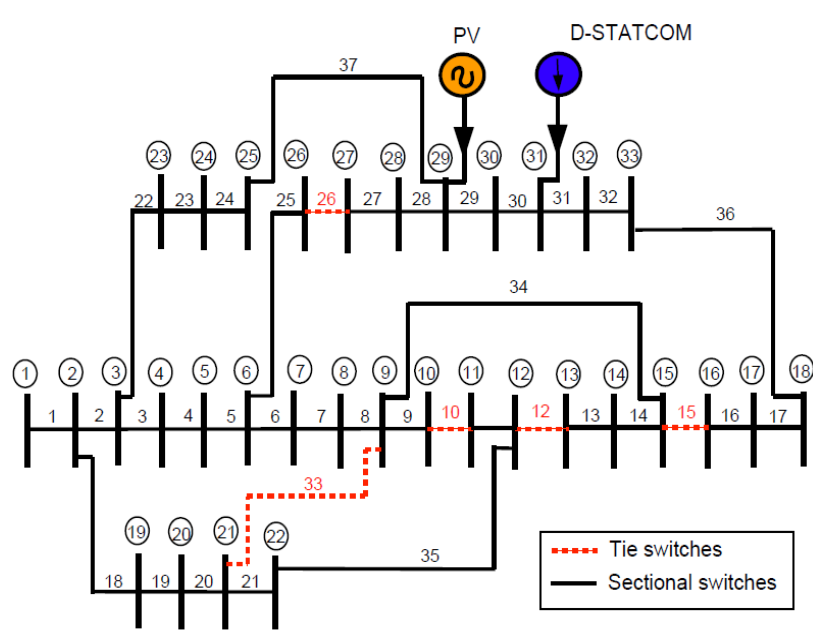

Fig. 8. Optimal configuration of 33 - bus test system.

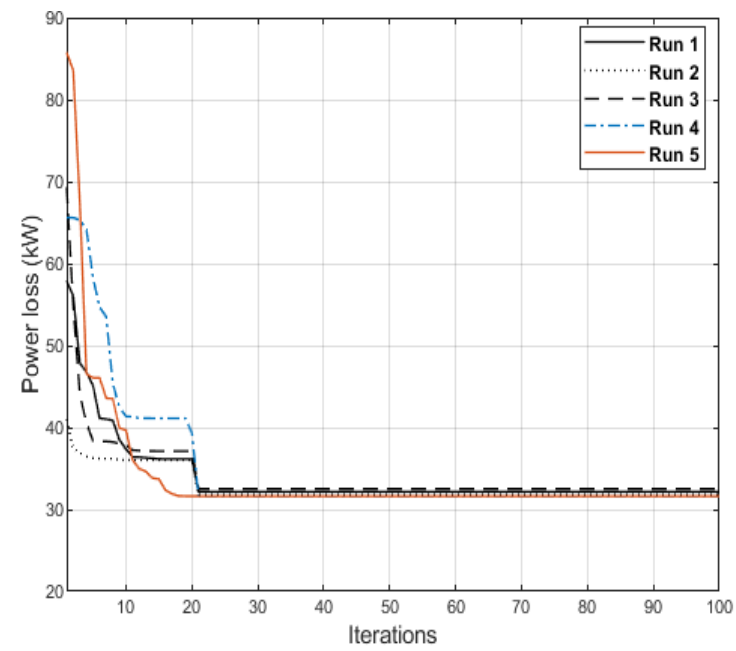

Fig. 9. Convergence characteristics of GOA for 33 - bus test system at nominal load condition for five independent runs.

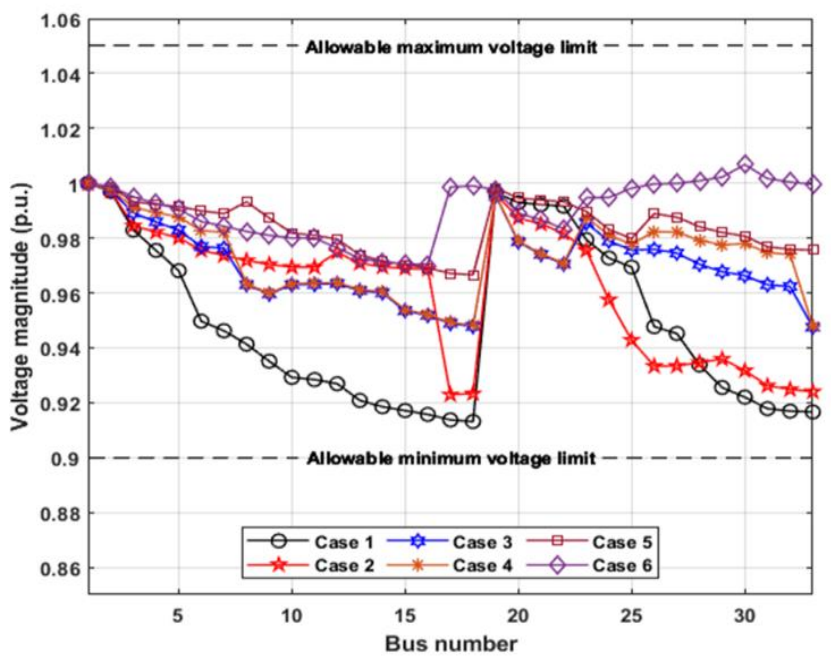

Fig. 10. Voltage profile of 33 - bus test system at nominal load condition. 


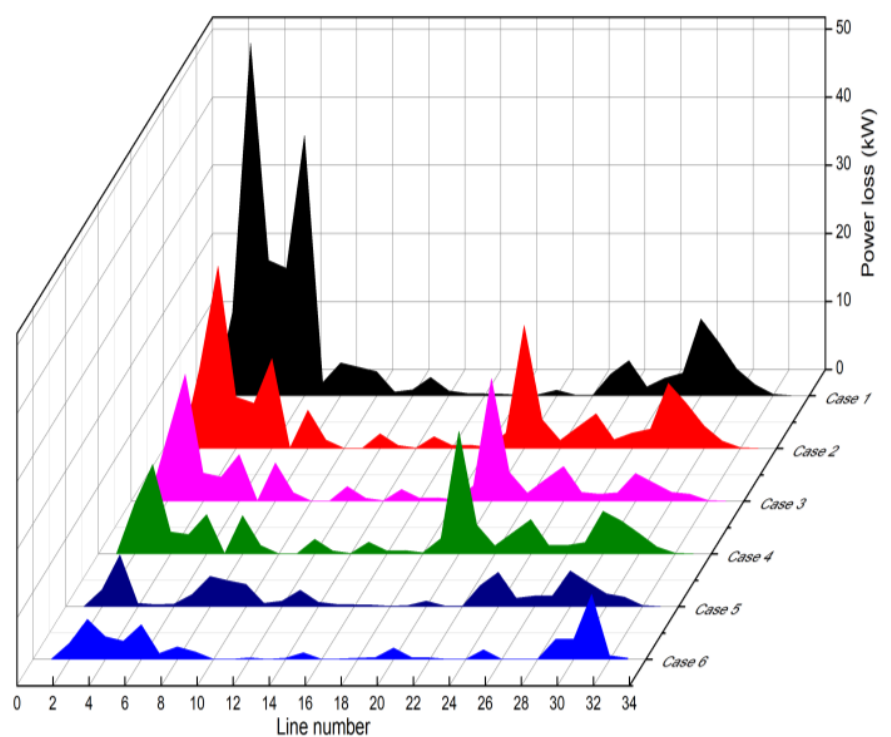

Fig. 11. Line losses of 33 - bus test system for different cases at nominal load condition.

TABLE II: OBTAINED RESUlTS OF 33 - Bus TEST SySTEM

\begin{tabular}{|c|c|c|c|c|}
\hline Case & Parameter & Light $(0.5)$ & Nominal (1.0) & Heavy (1.6) \\
\hline \multirow{3}{*}{ Case 1} & Open switches & $33,34,35,36,37$ & $33,34,35,36,37$ & $33,34,35,36,37$ \\
\hline & $P_{\text {Tloss }}(\mathrm{kW})$ & 47.07 & 202.68 & 575.36 \\
\hline & $\begin{array}{l}\Delta V_{d}(p . u) \\
V_{\min }(p . u) \\
\text { CPU time (s) }\end{array}$ & $\begin{array}{c}0.0399 \\
0.9583(18) \\
0.26\end{array}$ & $\begin{array}{c}0.0831 \\
0.9131(18) \\
0.27\end{array}$ & $\begin{array}{c}0.1406 \\
0.8528(18) \\
0.28\end{array}$ \\
\hline \multirow[t]{3}{*}{ Case 2} & Open switches & $7,14,9,32,37$ & $7,14,9,32,37$ & $7,14,9,32,37$ \\
\hline & $\begin{array}{l}P_{\text {Tloss }}(\mathrm{kW}) \\
\% \text { loss reduced } \\
\Delta V_{d}(p . u)\end{array}$ & $\begin{array}{c}33.27 \\
29.31 \\
0.0302\end{array}$ & $\begin{array}{c}139.55 \\
31.14 \\
0.0621\end{array}$ & $\begin{array}{c}380.45 \\
33.47 \\
0.1033\end{array}$ \\
\hline & $\begin{array}{l}V_{\min }(p . u) \\
\text { CPU time }(\mathrm{s})\end{array}$ & $\begin{array}{c}0.9698(32) \\
1.06\end{array}$ & $\begin{array}{c}0.9378(32) \\
1.07\end{array}$ & $\begin{array}{c}0.8967(32) \\
1.10\end{array}$ \\
\hline Case 3 & $\begin{array}{l}\text { Open switches } \\
\text { D-STATCOM (kVAr) } \\
P_{\text {Tloss }}(\mathrm{kW}) \\
\% \text { loss reduced } \\
\Delta V_{d}(p . u) \\
V_{\text {min }}(p . u)\end{array}$ & $\begin{array}{c}7,14,9,32,37 \\
511(31) \\
24.56 \\
47.82 \\
0.0154 \\
0.9744(33)\end{array}$ & $\begin{array}{c}7,14,9,32,37 \\
1029(30) \\
101.82 \\
49.76 \\
0.0376 \\
0.9475(33)\end{array}$ & $\begin{array}{c}7,14,9,32,37 \\
1658(31) \\
272.84 \\
52.57 \\
0.0517 \\
0.9134(33)\end{array}$ \\
\hline \multirow[t]{3}{*}{ Case 4} & $\begin{array}{l}\text { CPU time (s) } \\
\text { Open switches } \\
\text { SPV }(\mathrm{kW}) \\
P_{\text {Tloss }}(\mathrm{kW})\end{array}$ & $\begin{array}{c}1.08 \\
7,14,9,32,37 \\
569(30) \\
23.71\end{array}$ & $\begin{array}{c}1.12 \\
7,14,9,32,37 \\
1153(29) \\
98.10\end{array}$ & $\begin{array}{c}1.07 \\
7,14,9,32,37 \\
1877.1(29) \\
262.31\end{array}$ \\
\hline & $\begin{array}{l}\% \text { loss reduced } \\
\Delta V_{d}(p . u)\end{array}$ & $\begin{array}{c}49.62 \\
0.0119\end{array}$ & $\begin{array}{c}51.59 \\
0.0277\end{array}$ & $\begin{array}{c}54.40 \\
0.0449\end{array}$ \\
\hline & $V_{\min }(p . u)$ & $0.9746(33)$ & $0.9479(33)$ & $0.9140(33)$ \\
\hline \multirow[t]{4}{*}{ Case 5} & $\begin{array}{l}\text { CPU time (s) } \\
\text { Open switches }\end{array}$ & $\begin{array}{c}1.09 \\
33,34,35,36,37\end{array}$ & $\begin{array}{c}1.03 \\
33,34,35,36,37\end{array}$ & $\begin{array}{c}1.02 \\
33,34,35,36,37\end{array}$ \\
\hline & $\begin{array}{l}\text { D-STATCOM }(\mathrm{kVAr}) \\
\text { SPV array }(\mathrm{kW}) \\
P_{\text {Tloss }}(\mathrm{kW}) \\
\% \text { loss reduced } \\
\Delta V_{d}(p . u)\end{array}$ & $\begin{array}{c}1238.8(6) \\
619.47(29) \\
12.64 \\
73.14 \\
0.0087\end{array}$ & $\begin{array}{c}2000(25) \\
1250.2(29) \\
55.71 \\
72.51 \\
0.0217\end{array}$ & $\begin{array}{c}2200(29) \\
2031.8(29) \\
172.67 \\
69.98 \\
0.0130\end{array}$ \\
\hline & $V_{\min }(p . u)$ & $0.9827(17)$ & $0.9549(17)$ & $0.9111(17)$ \\
\hline & CPU time (s) & 0.08 & 0.05 & 0.055 \\
\hline \multirow[t]{7}{*}{ Case 6} & $\begin{array}{l}\text { Open switches } \\
\text { D-STATCOM (kVAr) }\end{array}$ & $\begin{array}{c}33,13,9,16,26 \\
963(29)\end{array}$ & $\begin{array}{c}33,12,10,15,26 \\
1983(29)\end{array}$ & $\begin{array}{c}33,12,9,36,25 \\
2200(29)\end{array}$ \\
\hline & SPV array $(\mathrm{kW})$ & $541(32)$ & $1379(31)$ & $2195(30)$ \\
\hline & $P_{\text {Tloss }}(\mathrm{kW})$ & 10.64 & 35.02 & 128.27 \\
\hline & $\%$ loss reduced & 77.39 & 82.72 & 77.70 \\
\hline & $\Delta V_{d}(p \cdot u)$ & 0.0018 & 0.0038 & 0.0222 \\
\hline & $V_{\min }(p . u)$ & $0.9850(14)$ & $0.9669(13)$ & $0.9257(18)$ \\
\hline & CPU time (s) & 1.12 & 1.09 & 1.07 \\
\hline
\end{tabular}


TABLE III: COMPARATIVE STUdy OF GOA FoR 33 - Bus TEST SYSTEM

\begin{tabular}{|c|c|c|c|c|c|}
\hline Case & Parameter & FWA [35] & Analytical [34] & MO-MFPA [29] & GOA \\
\hline \multirow[t]{4}{*}{ Case 2} & Open switches & $7,14,9,32,28$ & $7,9,14,28,31$ & $7,14,9,32,37$ & $7,14,9,32,37$ \\
\hline & $P_{\text {Tloss }}(\mathrm{kW})$ & 139.98 & 121.28 & 138.55 & 139.55 \\
\hline & $\%$ loss reduced & 30.93 & 42.31 & 31.88 & 31.14 \\
\hline & $V_{\min }(p . u)$ & 0.9413 & $0.9434(32)$ & $0.9417(30)$ & $0.9378(32)$ \\
\hline \multirow[t]{6}{*}{ Case 3} & Parameter & Fuzzy - GA [36] & Analytical [34] & MO-MFPA [29] & GOA \\
\hline & Open switches & $9,14,27,33,36$ & $7,9,14,28,31$ & $7,14,9,32,37$ & $7,14,9,32,37$ \\
\hline & D-STATCOM (kVAr) & 752 & $1125(30)$ & $1174.9(24)$ & $1029(30)$ \\
\hline & $P_{\text {Tloss }}(\mathrm{kW})$ & 132.87 & 92.77 & $94.37\left(131.93^{\mathrm{a}}\right)$ & 101.82 \\
\hline & $\%$ loss reduced & 34.2 & 56.08 & 53.2 & 49.76 \\
\hline & $V_{\min }(p . u)$ & 0.9727 & $0.9438(32)$ & $0.9704(33)$ & $0.9475(33)$ \\
\hline \multirow[t]{6}{*}{ Case 4} & Parameter & FWA [35] & Analytical [34] & MO-MFPA [29] & GOA \\
\hline & Open switches & $7,14,9,32,28$ & $7,9,14,28,31$ & $7,14,9,32,37$ & $7,14,9,32,37$ \\
\hline & SPV (kW) & 1072.7 & $1425(29)$ & $1056.2(20)$ & $1153(29)$ \\
\hline & $P_{\text {Tloss }}(\mathrm{kW})$ & 83.91 & 82.76 & $78.9\left(118.56^{\mathrm{a}}\right)$ & 98.10 \\
\hline & $\%$ loss reduced & 58.59 & 60.81 & 60.9 & 51.59 \\
\hline & $V_{\min }(p . u)$ & 0.9612 & $0.9443(32)$ & $0.9620(33)$ & $0.9479(33)$ \\
\hline \multirow[t]{6}{*}{ Case 5} & Parameter & BFOA [24] & Analytical [34] & MO-MFPA [29] & GOA \\
\hline & $\begin{array}{l}\text { Open switches } \\
\text { D-STATCOM (kVAr) }\end{array}$ & $\begin{array}{c}33,34,35,36,37 \\
1094.6(30)\end{array}$ & $\begin{array}{c}33,34,35,36,37 \\
1250(30)\end{array}$ & $\begin{array}{c}33,34,35,36,37 \\
1481(31)\end{array}$ & $\begin{array}{c}33,34,35,36,37 \\
2000(25)\end{array}$ \\
\hline & SPV array (kW) & $1239.8(10)$ & $2601(6)$ & $1323.6(33)$ & $1250.2(29)$ \\
\hline & $P_{\text {Tloss }}(\mathrm{kW})$ & 70.87 & 58.55 & 65.7 & 55.71 \\
\hline & $\%$ loss reduced & 65.00 & 72.28 & 67.4 & 72.51 \\
\hline & $V_{\min }(p . u)$ & 0.9615 & $0.9545(18)$ & $0.9612(29)$ & 0.9549 (17) \\
\hline \multirow[t]{6}{*}{ Case 6} & Parameter & Fuzzy - ACO [30] & Analytical [34] & MO-MFPA [29] & GOA \\
\hline & $\begin{array}{l}\text { Open switches } \\
\text { D-STATCOM (kVAr) }\end{array}$ & $\begin{array}{c}9,14,27,33,36 \\
1316(9)\end{array}$ & $\begin{array}{c}7,9,14,28,31 \\
1125(30)\end{array}$ & $\begin{array}{c}7,11,14,28,32 \\
1088.7(23)\end{array}$ & $\begin{array}{c}33,12,10,15,26 \\
1983(29)\end{array}$ \\
\hline & SPV array $(\mathrm{kW})$ & $740(10)$ & $1425(29)$ & $1266.8(21)$ & $1379(31)$ \\
\hline & $P_{\text {Tloss }}(\mathrm{kW})$ & 48.73 & 55.53 & 39.14 & 35.02 \\
\hline & $\%$ loss reduced & 75.95 & 73.71 & 80.6 & 82.72 \\
\hline & $V_{\min }(p . u)$ & - & $0.9447(32)$ & $0.9753(22)$ & $0.9669(13)$ \\
\hline
\end{tabular}

$\mathrm{a}$ - calculated value of power loss (in $\mathrm{kW}$ ).

\section{B. Test System 2}

The second test system is a 69 - bus distribution system having 5 tie switches (open switches) and 68 sectional switches (closed switches). The system total active and reactive power demands are $3.8 \mathrm{MW}$ and 2.7 MVAR, respectively. The power flow analysis is evaluated based on $S_{\text {base }}=100 \mathrm{MVA}$ and $V_{\text {base }}=12.66 \mathrm{kV}$. The system line and load data are taken from [37]. Similar to test system 1, this 69 - bus system also simulated for six cases under three different loading conditions. The D-STATCOM and PV array limits are the same as the previous test system.

The numerical results obtained for 69 - bus distribution system using GOA for six tested cases under three different loading conditions are presented in Table IV. It is observed that the base case power loss (in $\mathrm{kW}$ ) of the system at the light, nominal and heavy load conditions are 51.60, 225.06, and 652.96, respectively. From Table IV, it is observed that case 6 is more effective in power loss reduction and VP enhancement compared to other cases. For case 6, the optimal configuration is obtained after opening the switches 69,14 , 17, 21 and 55; and allocation of D-STATCOM and PV array at bus 61 with $1813 \mathrm{kVAr}$ and $1294 \mathrm{~kW}$, respectively is illustrated in Fig. 12.
The voltage profile characteristics of case 1 (base case) and case 6 (optimum case) at nominal load level are illustrated in Fig. 13. The line loss reduction for case 1 to 6 is illustrated in Fig. 14. It can be noticed that the line losses reducing drastically for case 1 to 6 at nominal load level. The simulated results obtained using the proposed GOA at nominal load level are presented in Table $\mathrm{V}$ and the same is compared with other methods existing in the literature. From Table V, it can be observed that the proposed GOA is performing better than the other existing methods in terms of power loss minimization and VP enhancement for all cases. 
(36) (37) (38) (39) (40) (41) (42) (43) (44) (45) (46)

\begin{tabular}{l|l|l|l|l|l|l|l|l|l|l|l|}
35 & 36 & 37 & 38 & 39 & 40 & 41 & 42 & 43 & 44 & 45 \\
\hline & & & & & & & & & & & \\
\hline
\end{tabular}

(1) (2) (3) (4) (5) (6) (7) (8) (9) (19) (11):(12) (13) (14) (15) (16) (17) (18) (19) (26) (21) (22) (23) (24) (25) (26) (27)

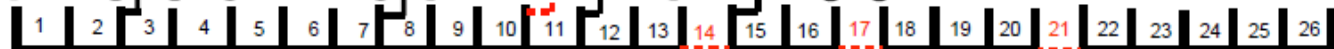

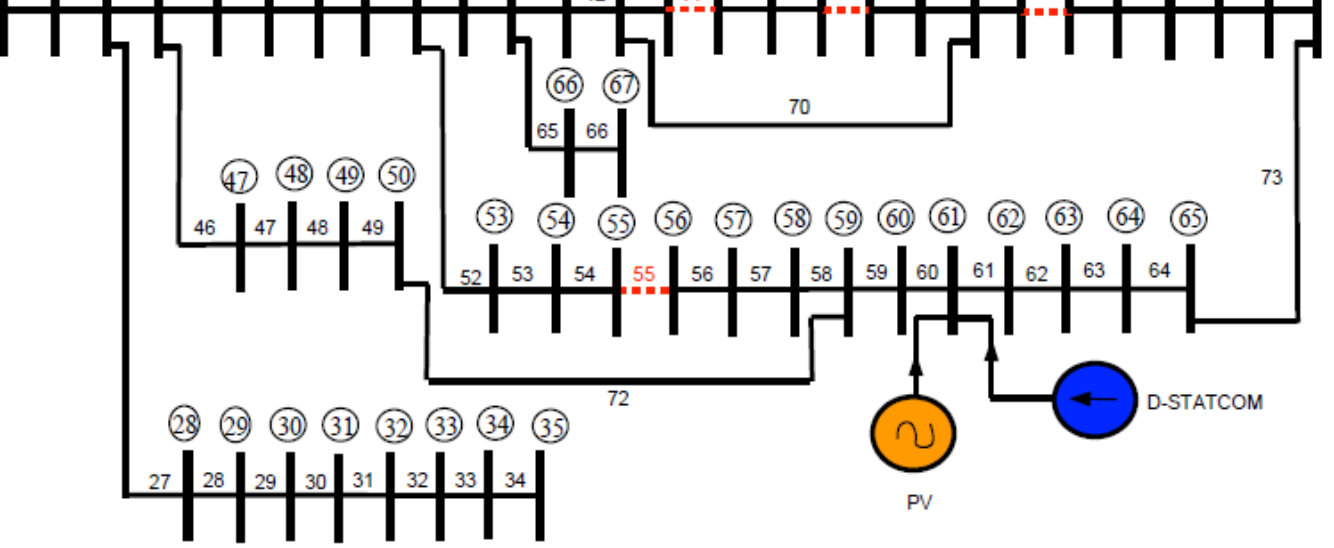

Fig. 12. Optimal configuration of 69 - bus test system.

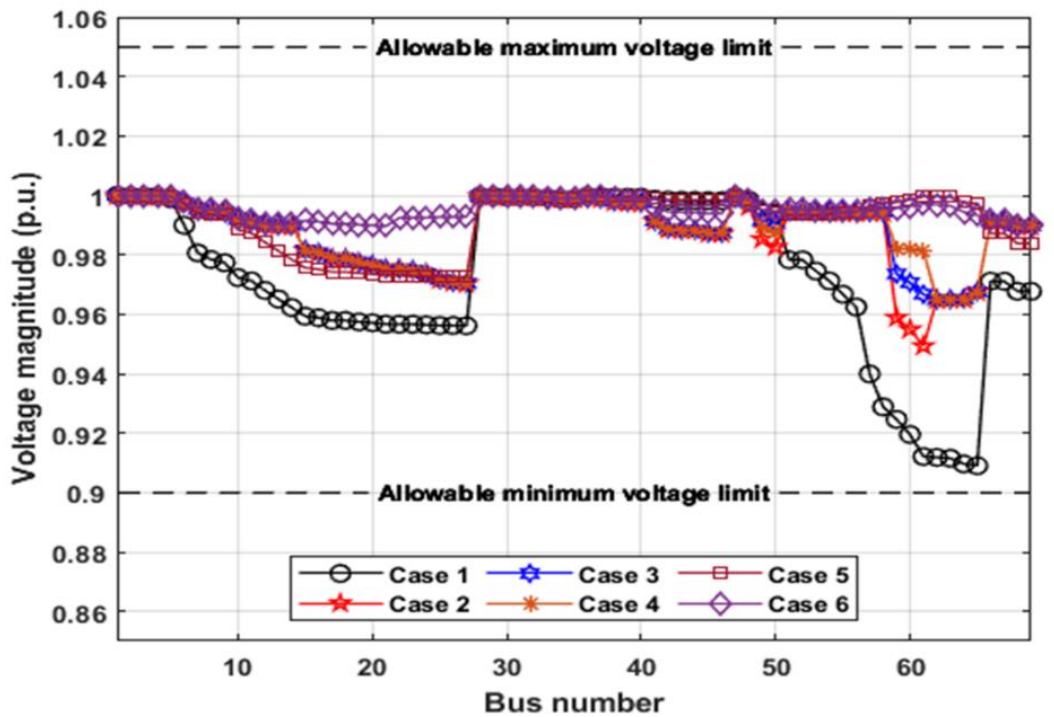

Fig. 13. Voltage profile of 69 - bus test system at nominal load condition.

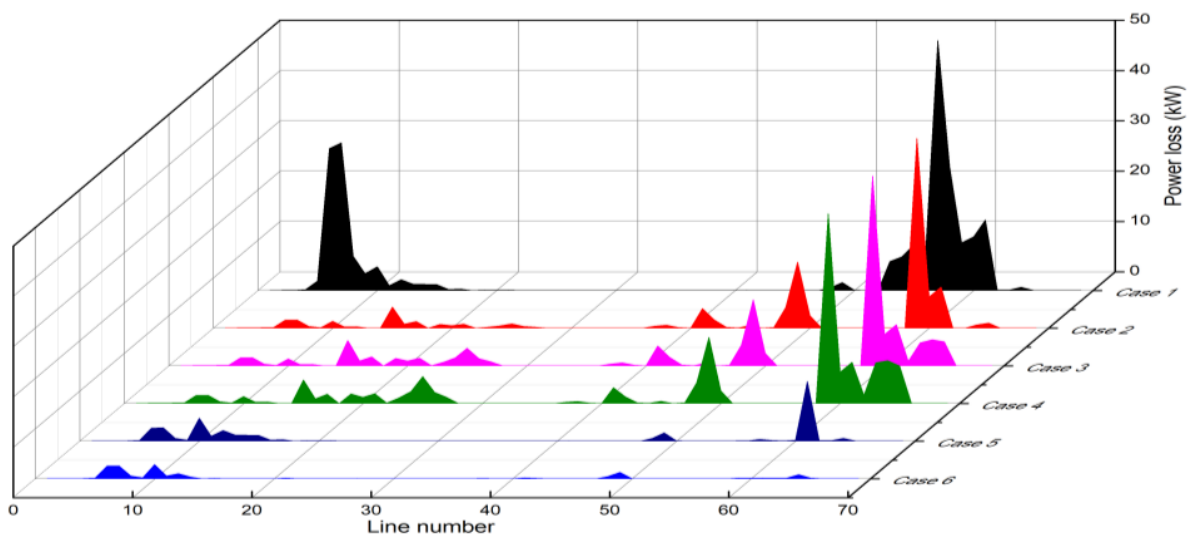

Fig. 14. Line losses of 69 - bus test system for different cases at nominal load condition. 
TABLE IV: OBTAINED RESULTS OF 69 - Bus TEST SySTEM

\begin{tabular}{|c|c|c|c|c|}
\hline Case & Parameter & Light $(0.5)$ & Nominal (1.0) & Heavy (1.6) \\
\hline \multirow[t]{5}{*}{ Case 1} & Open switches & $69,70,71,72,73$ & $69,70,71,72,73$ & $69,70,71,72,73$ \\
\hline & $P_{\text {Tloss }}(\mathrm{kW})$ & 51.60 & 225.06 & 652.96 \\
\hline & $\Delta V_{d}(p . u)$ & 0.0434 & 0.0910 & 0.1559 \\
\hline & $V_{\min }(p . u)$ & $0.9565(66)$ & $0.9089(66)$ & $0.8441(66)$ \\
\hline & CPU time (s) & 0.16 & 0.16 & 0.17 \\
\hline \multirow[t]{6}{*}{ Case 2} & Open switches & $69,14,71,61,58$ & $69,14,71,61,58$ & $69,14,71,61,58$ \\
\hline & $P_{\text {Tloss }}(\mathrm{kW})$ & 23.61 & 98.63 & 267.26 \\
\hline & $\%$ loss reduced & 54.24 & 56.17 & 59.07 \\
\hline & $\Delta V_{d}(p . u)$ & 0.0247 & 0.0502 & 0.0838 \\
\hline & $V_{\min }(p . u)$ & $0.9752(62)$ & $0.9492(62)$ & $0.9161(62)$ \\
\hline & CPU time (s) & 2.24 & 2.24 & 2.22 \\
\hline \multirow[t]{7}{*}{ Case 3} & Open switches & $69,14,71,61,58$ & $69,14,71,61,58$ & $69,14,71,61,58$ \\
\hline & $\begin{array}{l}\text { D-STATCOM } \\
\text { (kVAr) }\end{array}$ & $512.4(61)$ & $1038.6(62)$ & $1690(62)$ \\
\hline & $P_{\text {Tloss }}(\mathrm{kW})$ & 17.82 & 73.45 & 195.37 \\
\hline & $\%$ loss reduced & 65.46 & 67.36 & 70.07 \\
\hline & $\Delta V_{d}(p . u)$ & 0.0172 & 0.0506 & 0.0837 \\
\hline & $V_{\min }(p . u)$ & $0.9827(63)$ & $0.9496(62)$ & $0.9162(62)$ \\
\hline & CPU time (s) & 2.27 & 2.15 & 2.18 \\
\hline \multirow[t]{7}{*}{ Case 4} & Open switches & $69,14,71,61,58$ & $69,14,71,61,58$ & $69,14,71,61,58$ \\
\hline & SPV $(k W)$ & $713.37(61)$ & $1434.96(62)$ & $2312.53(61)$ \\
\hline & $P_{\text {Tloss }}(\mathrm{kW})$ & 12.44 & 50.92 & 134.19 \\
\hline & $\%$ loss reduced & 75.89 & 77.37 & 79.44 \\
\hline & $\Delta V_{d}(p . u)$ & 0.0051 & 0.0103 & 0.0166 \\
\hline & $V_{\min }(p . u)$ & $0.9839(65)$ & $0.9674(65)$ & $0.9469(65)$ \\
\hline & CPU time (s) & 2.17 & 2.16 & 2.19 \\
\hline \multirow[t]{8}{*}{ Case 5} & Open switches & $69,70,71,72,73$ & $69,70,71,72,73$ & $69,70,71,72,73$ \\
\hline & $\begin{array}{l}\text { D-STATCOM } \\
\text { (kVAr) }\end{array}$ & $912.3(61)$ & $1828.16(60)$ & $2400(61)$ \\
\hline & SPV array (kW) & $648.76(60)$ & $1301.28(60)$ & $2078.9(60)$ \\
\hline & $P_{\text {Tloss }}(\mathrm{kW})$ & 5.68 & 23.14 & 70.55 \\
\hline & $\%$ loss reduced & 89 & 89.71 & 89.19 \\
\hline & $\Delta V_{d}(p . u)$ & 0.0080 & 0.0162 & 0.0294 \\
\hline & $V_{\min }(p . u)$ & $0.9864(26)$ & $0.9725(26)$ & $0.9521(21)$ \\
\hline & CPU time (s) & 0.20 & 0.37 & 0.20 \\
\hline \multirow[t]{8}{*}{ Case 6} & Open switches & $69,14,71,25,53$ & $69,14,17,21,55$ & $69,14,17,21,55$ \\
\hline & $\begin{array}{l}\text { D-STATCOM } \\
\text { (kVAr) }\end{array}$ & $909(62)$ & $1813(61)$ & $2400(62)$ \\
\hline & SPV array (kW) & $642(60)$ & $1294(61)$ & $2019(62)$ \\
\hline & $P_{\text {Tloss }}(\mathrm{kW})$ & 4.43 & 15.42 & 48.31 \\
\hline & $\%$ loss reduced & 91.41 & 93.14 & 92.60 \\
\hline & $\Delta V_{d}(p \cdot u)$ & 0.0049 & 0.0139 & 0.0225 \\
\hline & $V_{\min }(p . u)$ & $0.9942(25)$ & 0.9835 (19) & 0.9734 (19) \\
\hline & CPU time (s) & 2.24 & 2.26 & 2.26 \\
\hline
\end{tabular}

\section{C. $\quad$ Test System 3}

The third test system is a 118 - bus distribution system having 15 tie switches (open switches) and 117 sectional switches (closed switches). The system total active and reactive power demands are $22.7 \mathrm{MW}$ and 17 MVAR, respectively. The power flow analysis is evaluated based on $S_{\text {base }}=100 \mathrm{MVA}$ and $V_{\text {base }}=11 \mathrm{kV}$. The system line and load data are taken from [38]. This test system is simulated for six cases under only nominal loading condition. The DSTATCOM and PV array limits are the same as previous test system however, the number of candidate bus locations for placement are six (i.e. three locations for D-STATCOM and three locations for PV array). The numerical results obtained for 118 - bus distribution system using GOA are compared for six tested cases are presented in Table VI. It is observed that the base case power loss (in $\mathrm{kW}$ ) of the system 1291.01 with minimum bus voltage of $0.8687 p . u$ at bus 77 and voltage deviation index of $0.092 \mathrm{p} . u$.

For case 6, the switches 16, 21, 39, 43, 32, 58, 124, 125, $71,97,128,85,130,108$ and 132 are opened for optimal system configuration and optimal location for D-STATCOM units are 50,75, 111 and optimal location for PV arrays are $51,92,109$. It is noticed that the percentage of power loss reduction achieved is slightly lower for case 2 to 4 when compared to MO-MFPA. However, for case 5 and 6 the proposed GOA is achieving a significant reduction in power loss. The optimal configuration of the distribution system for case 6 is shown in Fig. 15. The line loss reduction for case 1 to 6 is illustrated in Fig. 16. It can be noticed that the line losses reducing drastically for case 1 to 6 . However, the percentage loss reduction for case 5 is slightly higher than case 6 . This is because the system configuration (case 1) is unaltered. The performance analysis of the proposed GOA in terms of percentage power loss reduction and minimum bus 
voltage enhancement for all test systems at nominal load conditions are illustrated in Fig. 17 and Fig. 18. The algorithm parameter values for all test systems with six operating cases under three different load conditions are presented in Table VII.

TABLE V: COMPARATIVE STUDY OF GOA FOR 69 - Bus TEST SySTEM

\begin{tabular}{|c|c|c|c|c|}
\hline Case & Parameter & FWA [35] & MO-MFPA [29] & GOA \\
\hline \multirow[t]{4}{*}{ Case 2} & Open switches & $69,70,14,56,61$ & $69,18,15,54,61$ & $69,14,71,61,58$ \\
\hline & $P_{\text {Tloss }}(\mathrm{kW})$ & 98.59 & 97.95 & 98.63 \\
\hline & $\%$ loss reduced & 56.17 & 56.4 & 56.17 \\
\hline & $V_{\min }(p . u)$ & 0.9495 & $0.9579(61)$ & $0.9492(62)$ \\
\hline \multirow[t]{6}{*}{ Case 3} & Parameter & - & MO-MFPA [29] & GOA \\
\hline & Open switches & - & $69,18,15,54,61$ & $69,14,71,61,58$ \\
\hline & D-STATCOM (kVAr) & - & $1445.2(46)$ & $1038.6(62)$ \\
\hline & $P_{\text {Tloss }}(\mathrm{kW})$ & - & 75.7 & 73.45 \\
\hline & $\%$ loss reduced & - & 66.3 & 67.36 \\
\hline & $V_{\min }(p . u)$ & - & $0.9775(59)$ & $0.9496(62)$ \\
\hline \multirow[t]{5}{*}{ Case 4} & Parameter & FWA [35] & MO-MFPA [29] & GOA \\
\hline & $\begin{array}{l}\text { Open switches } \\
\text { SPY (kW) }\end{array}$ & $69,70,14,56,61$ & $69,18,15,54,61$ & $\begin{array}{c}69,14,71,61,58 \\
1434,96(62)\end{array}$ \\
\hline & $P_{\text {Tloss }}(\mathrm{kW})$ & 43.88 & 42.91 & 50.92 \\
\hline & $\%$ loss reduced & 80.49 & 80.92 & 77.37 \\
\hline & $V_{\min }(p . u)$ & 0.9720 & $0.9732(59)$ & $0.9674(65)$ \\
\hline \multirow[t]{7}{*}{ Case 5} & Parameter & WCA [25] & MO-MFPA [29] & GOA \\
\hline & Open switches & $69,70,71,72,73$ & $69,70,71,72,73$ & $69,70,71,72,73$ \\
\hline & D-STATCOM (kVAr) & 2694.9 & $1505.3(64)$ & $1828.16(60)$ \\
\hline & SPV array $(\mathrm{kW})$ & 3700 & $1092.3(65)$ & $1301.28(60)$ \\
\hline & $P_{\text {Tloss }}(\mathrm{kW})$ & 33.34 & 82.9 & 23.14 \\
\hline & $\%$ loss reduced & 85.18 & 63.1 & 89.71 \\
\hline & $V_{\min }(p . u)$ & $0.9950(15)$ & $0.9685(65)$ & $0.9725(26)$ \\
\hline \multirow[t]{7}{*}{ Case 6} & Parameter & - & MO-MFPA [29] & GOA \\
\hline & Open switches & - & $10,16,44,55,64$ & $69,14,17,21,55$ \\
\hline & D-STATCOM (kVAr) & - & $1025.3(65)$ & $1813(61)$ \\
\hline & SPV array $(\mathrm{kW})$ & - & $1396.9(41)$ & $1294(61)$ \\
\hline & $P_{\text {Tloss }}(\mathrm{kW})$ & - & 41.73 & 15.42 \\
\hline & $\%$ loss reduced & - & 81.5 & 93.14 \\
\hline & $V_{\min }(p . u)$ & - & $0.9804(64)$ & 0.9835 (19) \\
\hline
\end{tabular}

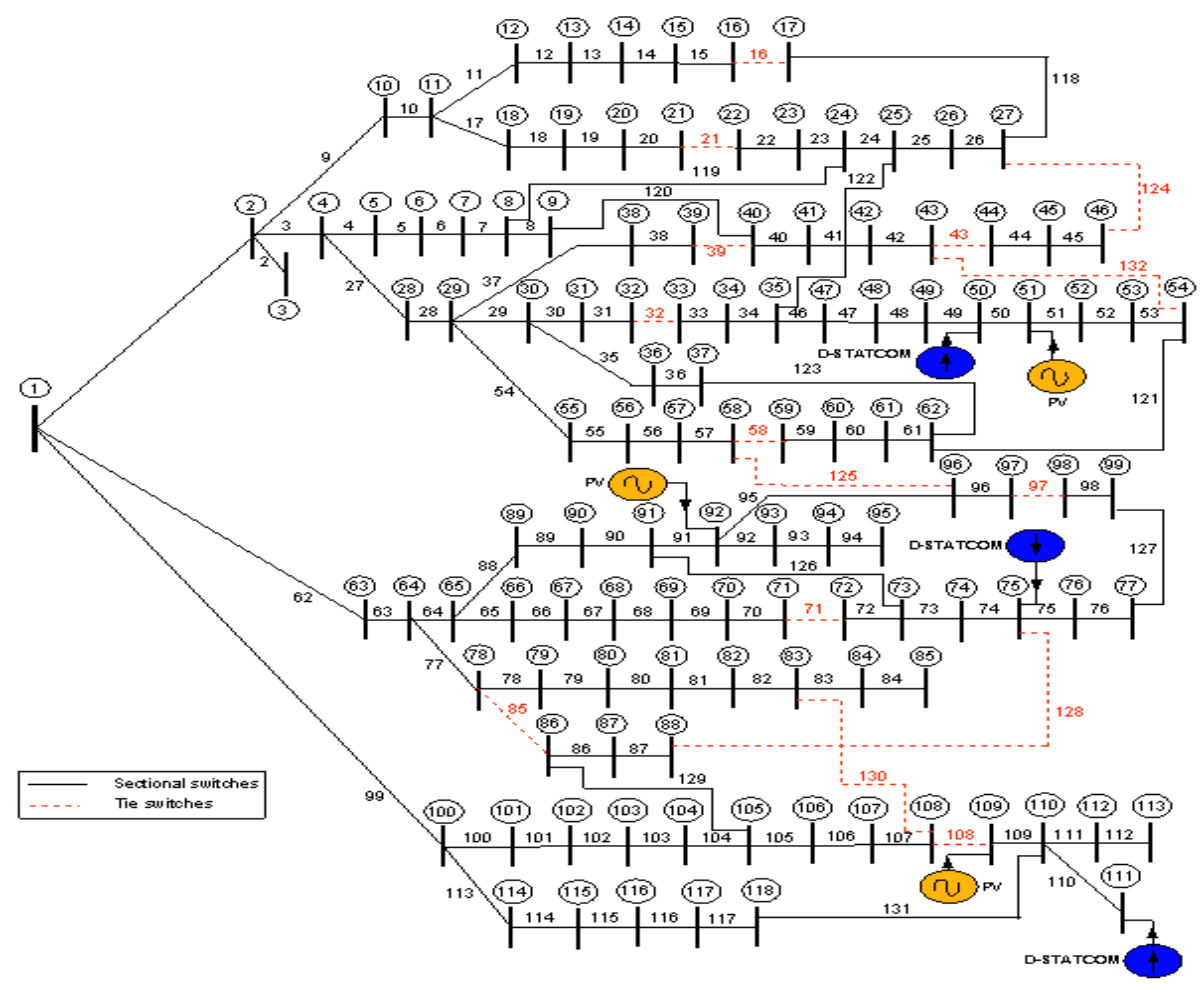

Fig. 15. Optimal configuration of 118 - bus test system. 


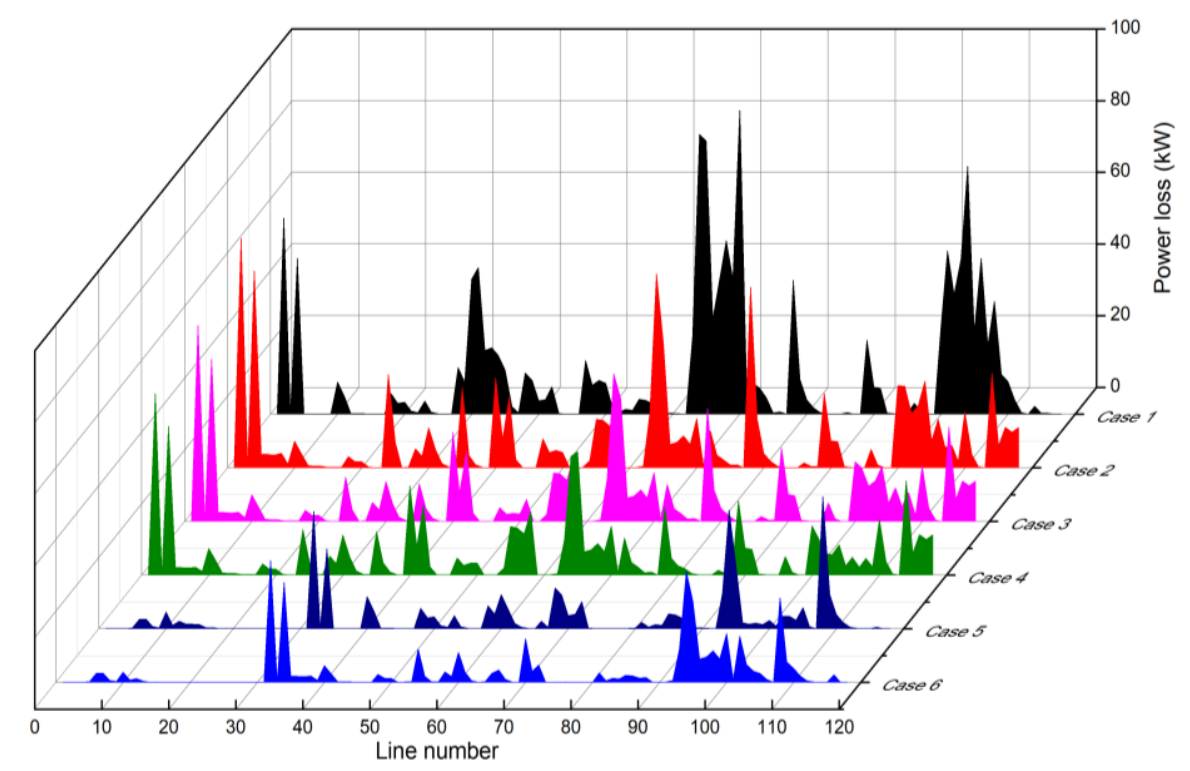

Fig. 16. Line losses of 118 - bus test system for different cases.

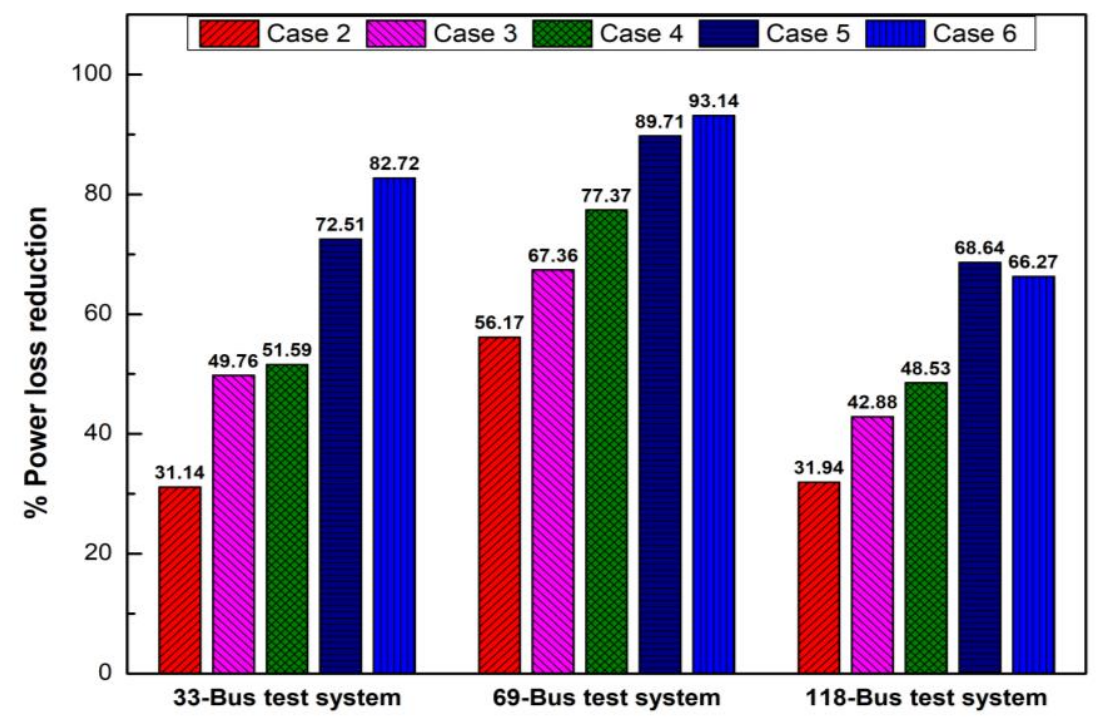

Fig. 17. Percentage of power loss reduction obtained using GOA for all test systems.

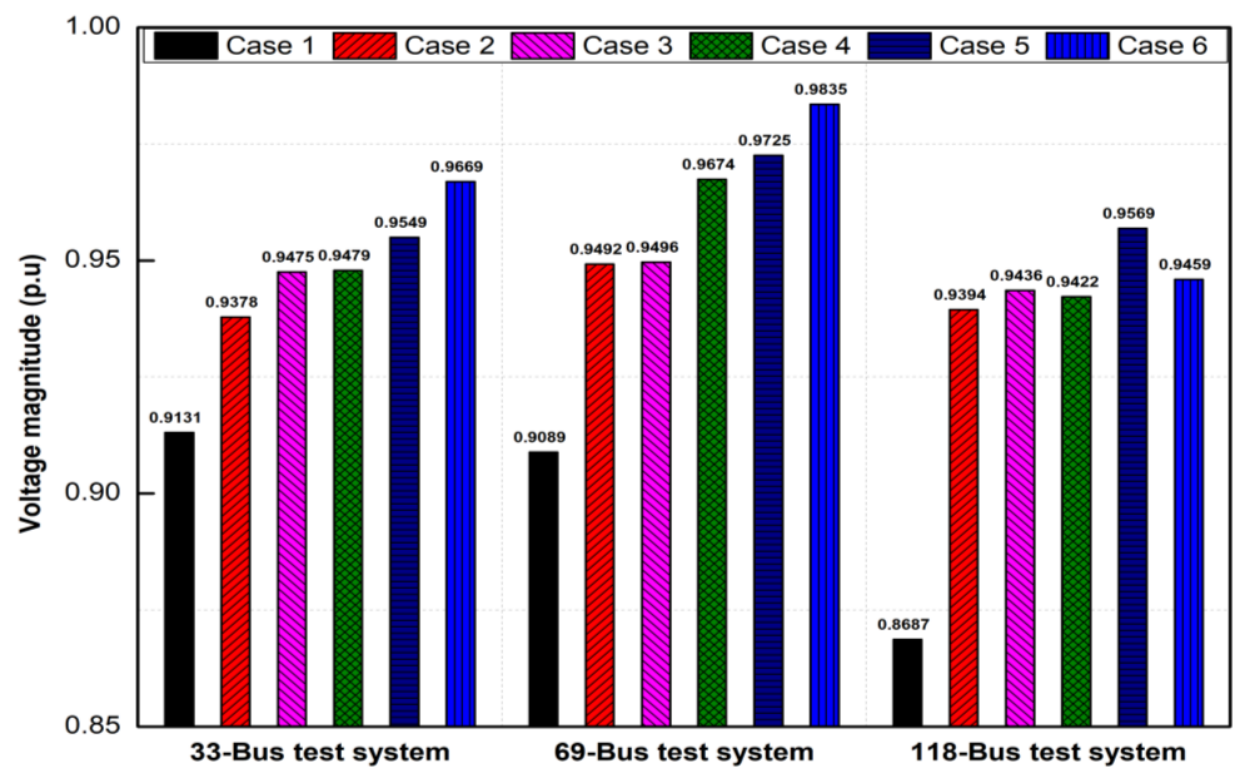

Fig. 18. Minimum bus voltage obtained using GOA for all test systems with six test cases. 
TABLE VI: COMPARATIVE STUdy OF GOA For 118 - Bus TeST SySTEM

\begin{tabular}{|c|c|c|c|}
\hline Case & Parameter & MO-MFPA [29] & GOA \\
\hline \multirow[t]{4}{*}{ Case 2} & Open switches & $\begin{array}{c}42,25,22,121,50,58,39,95 \\
71,74,97,129,130,109,34\end{array}$ & $\begin{array}{c}25,23,39,43,34,58,124,95 \\
71,97,74,129,130,109,51\end{array}$ \\
\hline & $P_{\text {Tloss }}(\mathrm{kW})$ & 854 & 878.57 \\
\hline & $\%$ loss reduced & 32.90 & 31.94 \\
\hline & $V_{\min }(p . u)$ & 0.9310 & $0.9394(74)$ \\
\hline \multirow[t]{8}{*}{ Case 3} & Parameter & MO-MFPA [29] & GOA \\
\hline & Open switches & $\begin{array}{c}45,25,19,121,122,58,39, \\
125,70,127,128,81,130, \\
131,132\end{array}$ & $\begin{array}{c}25,23,39,43,34,58,124,95 \\
71,97,74,129,130,109,51\end{array}$ \\
\hline & D-STATCOM (kVAr) & $1840(89)$ & $1857.74(51)$ \\
\hline & & & $1900(80)$ \\
\hline & & & $1874.49(108)$ \\
\hline & $P_{\text {Tloss }}(\mathrm{kW})$ & 636 & 737.30 \\
\hline & $\%$ loss reduced & 50 & 42.88 \\
\hline & $V_{\min }(p . u)$ & 0.9480 & $0.9436(74)$ \\
\hline \multirow[t]{8}{*}{ Case 4} & Parameter & MO-MFPA [29] & GOA \\
\hline & Open switches & $\begin{array}{c}42,25,22,121,50,58,39,95 \\
71,74,97,129,130,109,34\end{array}$ & $\begin{array}{c}25,23,39,43,34,58,124,95 \\
71,97,74,129,130,109,51\end{array}$ \\
\hline & SPV $(k W)$ & $179(111)$ & $2000(50)$ \\
\hline & & & $1999.5(80)$ \\
\hline & & & $2000(109)$ \\
\hline & $P_{\text {Tloss }}(\mathrm{kW})$ & 589 & 664.42 \\
\hline & $\%$ loss reduced & 53.7 & 48.53 \\
\hline & $V_{\min }(p \cdot u)$ & 0.958 & $0.9422(74)$ \\
\hline \multirow[t]{11}{*}{ Case 5} & Parameter & MO-MFPA [29] & GOA \\
\hline & Open switches & $\begin{array}{c}118,119,120,121,122,123 \\
124,125,126,127,128,129 \\
13,131,132\end{array}$ & $\begin{array}{c}118,119,120,121,122,123 \\
124,125,126,127,128,129 \\
13,131,132\end{array}$ \\
\hline & D-STATCOM (kVAr) & $1612(96)$ & $1900(49)$ \\
\hline & & & $1868.5(71)$ \\
\hline & & & $1899.6(110)$ \\
\hline & SPV array $(\mathrm{kW})$ & $1517(77)$ & $2000(49)$ \\
\hline & & & $2000(74)$ \\
\hline & & & $2000(110)$ \\
\hline & $P_{\text {Tloss }}(\mathrm{kW})$ & 623 & 404.85 \\
\hline & $\%$ loss reduced & 51 & 68.64 \\
\hline & $V_{\min }(p . u)$ & 0.9520 & $0.9569(98)$ \\
\hline \multirow[t]{11}{*}{ Case 6} & Parameter & MO-MFPA [29] & GOA \\
\hline & Open switches & $\begin{array}{c}42,25,21,121,48,60,39 \\
125,126,68,76,129,130, \\
109,33\end{array}$ & $\begin{array}{c}16,21,39,43,32,58,124 \\
125,71,97,128,85,130,108, \\
132\end{array}$ \\
\hline & D-STATCOM (kVAr) & $1568(97)$ & $1868.7(50)$ \\
\hline & & & $1269.47(75)$ \\
\hline & & & $1104.7(111)$ \\
\hline & SPV array $(\mathrm{kW})$ & $1656(109)$ & $1743.96(51)$ \\
\hline & & & $1989.9(92)$ \\
\hline & & & $1919.6(109)$ \\
\hline & $P_{\text {Tloss }}(\mathrm{kW})$ & 544 & 435.39 \\
\hline & $\%$ loss reduced & 57.2 & 66.27 \\
\hline & $V_{\min }(p . u)$ & 0.9654 & $0.9459(71)$ \\
\hline
\end{tabular}

TABLE VII: GOA PARAMETERS FOR TEST SYSTEMS

\begin{tabular}{lccc}
\hline Entity & $33-$ bus system & $69-$ bus system & 118 - bus system \\
\hline Population size, $N$ & 50 & 50 & 50 \\
Maximum number of & 200 & 200 & 200 \\
iterations, iter $_{\max }$ & 1.0 & 1.0 & 1.0 \\
$c_{\max }$ & 0.00004 & 0.00004 & 0.00004 \\
$c_{\text {min }}$ & & & \\
\hline
\end{tabular}

\section{CONCLUSIONS}

In this paper, a new GOA has been presented for solving network reconfiguration problem in presence of DSTATCOM units and PV arrays. The proposed algorithm is employed for loss minimization and VP enhancement. The
GOA has been successfully tested on 33, 69 and 118 - bus distribution systems with six different test cases under three different loading conditions with the objective of power loss minimization and VP enhancement. The six different test cases are base case, only reconfiguration, D-STATCOM allocation after reconfiguration, PV array allocation after reconfiguration, allocation of D-STATCOM and PV array on 
the system with standard configuration, network reconfiguration in presence of D-STATCOM and PV array. Among the six test cases, network reconfiguration in presence of D-STATCOM and PV array is found to be better when compared to other test cases. For 33 - bus system, the percentage power loss reduction obtained is 82.72 with a minimum voltage deviation of 0.0038 p.u at nominal load condition. Similarly, for 69 and 118 - bus systems the percentage power loss reduction is 93.14 and 66.27 with minimum voltage deviation of 0.0139 p.u and 0.0140 p.u, respectively. It is also noticed that the minimum bus voltage $(p . u)$ is improved from case 2 to case 6 for 69 - bus system is $0.9492,0.9496,0.9672,0.9725$ and 0.9835 , respectively. Simulated results obtained are compared with other existing methods in the literature shows the superiority of the proposed GOA.

\section{ACKNOWLEDGMENT}

This research work was supported by Vellore Institute of Technology, Vellore, India.

\section{REFERENCES}

[1] A. Merlin, and H. Back, "Search for a minimal loss operating spanning tree configuration in an urban power distribution system," Proceeding in 5thpower system computation conf. (PSCC), pp. 1-18, Cambridge, U.K, 1975.

[2] D. Shirmohammadi, and H. W. Hong, "Reconfiguration of electric distribution networks for resistive line losses reduction," IEEE Trans. on Power Delivery, vol. 4, no. 2, pp. 14982-8, Apr 1989.

[3] S. Civanlar, J. J. Grainger, H. Yin, and S. S. Lee, "Distribution feeder reconfiguration for loss reduction," IEEE Trans. on Power Delivery, vol. 3, no, 3, pp. 1217-23, July 1988.

[4] M. E. Baran, and F. F. Wu, "Network reconfiguration in distribution systems for loss reduction and load balancing," IEEE Trans. on Power delivery, vol. 4, no. 2, pp. 1401-7, Apr 1989.

[5] B. Sultana, M. W. Mustafa, U. Sultana, and A. Rauf, "Review on reliability improvement and power loss reduction in distribution system via network reconfiguration," Renew Sustain Energy Rev., vol. 66, pp. 297-310, 2016.

[6] I. Sarantakos, D. M. Greenwood, J. Yi, S. R. Blake, and P. C. Taylor, "A method to include component condition and substation reliability into distribution system reconfiguration," International Journal of Electrical Power \& Energy Systems, vol. 109, no. 1, pp. 122-38, July 2019.

[7] R. H. A. Zubo, G. Mokryani, H. S. Rajamani, J. Aghaei, T. Niknam, and P. Pillai, "Operation and planning of distribution networks with integration of renewable distributed generators considering uncertainties: A review," Renew Sustain Energy Rev, vol. 72, pp 1177-98, Oct 2016.

[8] K. Mahmoud, N. Yorino, and A. Ahmed, "Optimal Distributed Generation Allocation in Distribution Systems for Loss Minimization," IEEE Trans. on Power Systems, vol. 31, no. 2, pp. 960-9, 2016

[9] B. Jeddi B, V. Vahidinasab, P. Ramezanpour, J. Aghaei, M. Shafiekhah, and J. P. Catalão, "Robust optimization framework for dynamic distributed energy resources planning in distribution networks,' International Journal of Electrical Power \& Energy Systems, vol. 110, no. 1, pp. 419-33, Sep 2019.

[10] S. Saha, and V. Mukherjee, "Optimal placement and sizing of DGs in RDS using chaos embedded SOS algorithm," IET Generation, Transmission \& Distribution, vol. 10, no. 14, pp. 3671-80, Nov 2016.

[11] R. Sanjay, T. Jayabarathi, T. Raghunathan, V. Ramesh, and N. Mithulananthan, "Optimal allocation of distributed generation using hybrid grey wolf optimizer," IEEE Access, vol. 5, pp. 14807-18, July 2017.

[12] R. S. Rao, K. Ravindra, K. Satish, S. V. Narasimham, "Power loss minimization in distribution system using network reconfiguration in the presence of distributed generation," IEEE Trans. on Power Systems, vol. 28, no. 1, pp. 317-25, May 2012.
[13] H. R. Esmaeilian, and R. Fadaeinedjad, "Energy loss minimization in distribution systems utilizing an enhanced reconfiguration method integrating distributed generation," IEEE Systems Journal, vol. 9, no. 4, pp. 1430-9, Aug 2014.

[14] E. Mahboubi-Moghaddam, M. R. Narimani, M. H. Khooban, and A. Azizivahed, "Multi-objective distribution feeder reconfiguration to improve transient stability, and minimize power loss and operation cost using an enhanced evolutionary algorithm at the presence of distributed generations," International Journal of Electrical Power \& Energy Systems, vol. 76, no. 1, pp. 35-43, Mar 2016.

[15] A. Lotfipour, and H. Afrakhte, "A discrete Teaching-Learning-Based Optimization algorithm to solve distribution system reconfiguration in presence of distributed generation," International Journal of Electrical Power \& Energy Systems, vol. 82, no. 1, pp. 264-73, Nov 2016.

[16] T. T. Nguyen, A. V. Truong, and T. A. Phung, "A novel method based on adaptive cuckoo search for optimal network reconfiguration and distributed generation allocation in distribution network," International Journal of Electrical Power \& Energy Systems, vol. 78, no. 1, pp. 801-15, Jun 2016.

[17] K. Jasthi, and D. Das, "Simultaneous distribution system reconfiguration and DG sizing algorithm without load flow solution," IET Generation, Transmission \& Distribution, vol. 12, no. 6, pp 1303-13, Oct 2017.

[18] I. B. Hamida, S. B. Salah, F. Msahli, and M. F. Mimouni, "Optimal network reconfiguration and renewable DG integration considering time sequence variation in load and DGs," Renewable Energy, vol. 121, no. 1, pp. 66-80, Jun 2018.

[19] K. S. Sambaiah, and T. Jayabarathi, "Optimal reconfiguration and renewable distributed generation allocation in electric distribution systems", International Journal of Ambient Energy, pp. 1-14, Mar 2019. https://doi.org/01430750.2019.1583604

[20] M. Farhoodnea, A. Mohamed, H. Shareef, and H. Zayandehroodi, "Optimum D-STATCOM placement using firefly algorithm for power quality enhancement," In 2013 IEEE 7th international power engineering and optimization conference (PEOCO), vol. 3, pp. 98102, Langkawi, Jun 2013.

[21] S. A. Taher, and S. A. Afsari, "Optimal location and sizing of DSTATCOM in distribution systems by immune algorithm," International Journal of Electrical Power \& Energy Systems, vol. 60 , no. 1, pp. 34-44, Sep 2014.

[22] T. Yuvaraj, K. R. Devabalaji, and K. Ravi, "Optimal placement and sizing of DSTATCOM using harmony search algorithm," Energy Procedia, vol. 79, no. 1, pp. 759-65, Nov 2015.

[23] S. Devi, and M. Geethanjali, "Optimal location and sizing determination of Distributed Generation and DSTATCOM using Particle Swarm Optimization algorithm," International Journal of Electrical Power \& Energy Systems, vol. 62, no. 1, pp. 562-70, Nov 2014.

[24] K. R. Devabalaji, and K. Ravi, "Optimal size and siting of multiple DG and DSTATCOM in radial distribution system using Bacterial Foraging Optimization Algorithm," Ain Shams Engineering Journal, vol. 7, no. 3, pp. 959-71, Sep 2016.

[25] A. A. El-Ela, R. A. El-Sehiemy, and A. S. Abbas, "Optimal placement and sizing of distributed generation and capacitor banks in distribution systems using water cycle algorithm," IEEE Systems Journal, vol. 12, no. 4, pp. 3629-36, Feb 2018.

[26] J. H. Teng, "A direct approach for distribution system load flow solutions," IEEE Trans. on Power Delivery, vol. 18, no. 3, pp. 882-7, July 2003.

[27] D. H. Thukaram, H. W. Banda, and J. Jerome, "A robust three phase power flow algorithm for radial distribution systems," Electric Power Systems Research, vol. 50, no. 3, pp. 227-36, Jun 1999.

[28] A. M. Imran, and M. A. Kowsalya, "A new power system reconfiguration scheme for power loss minimization and voltage profile enhancement using fireworks algorithm," International Journal of Electrical Power \& Energy Systems, vol. 62, no.1, pp. 312 22, Nov 2014

[29] S. Ganesh, and R. Kanimozhi, "Meta-heuristic technique for network reconfiguration in distribution system with photovoltaic and DSTATCOM," IET Generation, Transmission \& Distribution, vol. 12 no. 20, pp. 4524-35, Sep 2018.

[30] H. B. Tolabi, M. H. Ali, and M. Rizwan Simultaneous reconfiguration, optimal placement of DSTATCOM, and photovoltaic array in a distribution system based on fuzzy-ACO approach. IEEE Transactions on sustainable Energy. 2014 Nov 20;6(1):210-8

[31] S. Saremi, S. Mirjalili, and A. Lewis, "Grasshopper optimisation algorithm: theory and application," Advances in Engineering Software, vol. 105, no. 1, pp. 30-47, Mar 2017. 
[32] U. Sultana, A. B. Khairuddin, B. Sultana, N. Rasheed, S. H. Qazi, and N. R. Malik, "Placement and sizing of multiple distributed generation and battery swapping stations using grasshopper optimizer algorithm," Energy, vol. 15, no. 165, Dec 2018.

[33] R. Rajaram, K. S. Kumar, and N. Rajasekar, "Power system reconfiguration in a radial distribution network for reducing losses and to improve voltage profile using modified plant growth simulation algorithm with Distributed Generation (DG)," Energy Reports, vol. 1, pp. 116-22, Nov 2015.

[34] D. Q. Hung, N. Mithulananthan, R. C. Bansal, "A combined practical approach for distribution system loss reduction", International Journal of Ambient Energy, vol. 36, no. 3, pp. 123-31, May 2015.

[35] A. M. Imran, M. Kowsalya, and D. P. Kothari, "A novel integration technique for optimal network reconfiguration and distributed generation placement in power distribution networks," International Journal of Electrical Power \& Energy Systems, vol. 63, no. 1, pp. 461-72, Dec 2014.

[36] M. Mohammadi, A. M. Rozbahani, and S. Bahmanyar, "Power loss reduction of distribution systems using BFO based optimal reconfiguration along with DG and shunt capacitor placement simultaneously in fuzzy framework," Journal of Central South University, vol. 24, no. 1, pp. 90-103, Jan 2017.

[37] J. S. Savier, and D. Das, "Impact of network reconfiguration on loss allocation of radial distribution systems," IEEE Transactions on Power Delivery, vol. 22, no. 4, pp. 2473-80, Oct 2007.

[38] D. Zhang, Z. Fu, and L. Zhang, "An improved TS algorithm for lossminimum reconfiguration in large-scale distribution systems," Electric Power Systems Research, vol. 77, no. 5, pp. 685-94, Apr 2007.

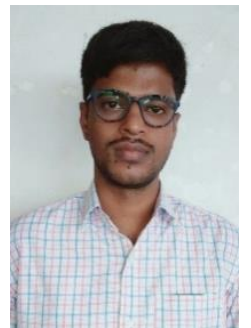

Kola Sampangi Sambaiah obtained his Bachelor's degree in electrical and electronics engineering from Priyadarshini Institute of Technology, Tirupati, India, in 2012, Master's degree in power electronics from Kuppam engineering college, Kuppam, India, in 2016 Currently, he is pursuing Ph.D. in Vellore institute of technology, Vellore, India. His current research interests are in optimization, soft computing, and distributed generation allocation in power systems.

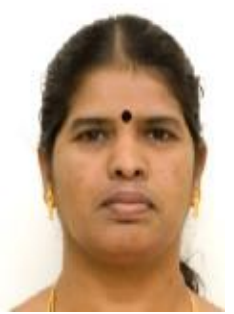

T Jayabarathi obtained her Bachelor's degree in electrical engineering from Dharwar University, Dharwar, India, in 1985, Master's degree in power systems from Annamalai University, India, and Ph.D. from College of Engineering, Guindy, Anna University, Chennai, India, in 2000. Currently, she is Senior Professor, School of Electrical Engineering, VIT University, Vellore, India. Her current research interests are in optimization, soft computing, and economic dispatch of power systems. 